\title{
Hiring Through Referrals in a Labor Market with Adverse Selection
}

Citation for published version (APA):

Dariel, A., Riedl, A., \& Siegenthaler, S. (2019). Hiring Through Referrals in a Labor Market with Adverse Selection. Maastricht University, Graduate School of Business and Economics. GSBE Research Memoranda No. 009 https://doi.org/10.26481/umagsb.2019009

Document status and date:

Published: 11/04/2019

DOI:

10.26481/umagsb.2019009

Document Version:

Publisher's PDF, also known as Version of record

\section{Please check the document version of this publication:}

- A submitted manuscript is the version of the article upon submission and before peer-review. There can be important differences between the submitted version and the official published version of record.

People interested in the research are advised to contact the author for the final version of the publication, or visit the DOI to the publisher's website.

- The final author version and the galley proof are versions of the publication after peer review.

- The final published version features the final layout of the paper including the volume, issue and page numbers.

Link to publication

\footnotetext{
General rights rights.

- You may freely distribute the URL identifying the publication in the public portal. please follow below link for the End User Agreement:

www.umlib.nl/taverne-license

Take down policy

If you believe that this document breaches copyright please contact us at:

repository@maastrichtuniversity.nl

providing details and we will investigate your claim.
}

Copyright and moral rights for the publications made accessible in the public portal are retained by the authors and/or other copyright owners and it is a condition of accessing publications that users recognise and abide by the legal requirements associated with these

- Users may download and print one copy of any publication from the public portal for the purpose of private study or research.

- You may not further distribute the material or use it for any profit-making activity or commercial gain

If the publication is distributed under the terms of Article $25 \mathrm{fa}$ of the Dutch Copyright Act, indicated by the "Taverne" license above, 


\section{Maastricht University}

Aurelie Dariel, Arno Riedl, Simon Siegenthaler

Hiring Through Referrals in a Labor Market with Adverse Selection

RM/19/009

\section{GSBE}

Maastricht University School of Business and Economics

Graduate School of Business and Economics

P.O Box 616

NL- 6200 MD Maastricht

The Netherlands 


\title{
Hiring Through Referrals in a Labor Market with Adverse Selection
}

\author{
Aurelie Dariel $^{*} \quad$ Arno Riedl ${ }^{\ddagger} \quad$ Simon Siegenthaler ${ }^{\S}$
}

April 8, 2019

\begin{abstract}
Information asymmetries can prevent markets from operating efficiently. An important example is the labor market, where employers face uncertainty about the productivity of job candidates. We examine theoretically and with laboratory experiments three key questions related to hiring via referrals when employees have private information about their productivity. First, do firms use employee referrals when there are social ties between a current employee and a future employee? Second, does the existence of social ties and hiring through employee referrals indeed alleviate adverse selection relative to when social ties do not exist? Third, does the existence of social ties have spill-over effects on wages and hiring in competitive labor markets? The answers to all three questions are affirmative. However, despite the identified positive effect of employment referrals, hiring decisions fall short of the (second-best) efficient outcome. We identify risk aversion as a potential reason for this.
\end{abstract}

JEL Classification: C92, D82, D85, E20

Keywords: Adverse selection, labor market, employee referrals, social networks

${ }^{*}$ New York University Abu Dhabi. Division of Social Science, New York University Abu Dhabi, P.O. Box 129188, Abu Dhabi, United Arab Emirates, phone: +971 2-628-4000, e-mail: apd5@nyu.edu.

${ }^{\ddagger}$ CESifo, IZA, Netspar, Department of Economics (AE1), School of Business and Economics, Maastricht University, P.O. Box 616, 6200 MD Maastricht, the Netherlands, phone: +31 43-38-84982, e-mail: a.riedl@maastrichtuniversity.nl.

${ }^{\S}$ Naveen Jindal School of Management, University of Texas at Dallas, Richardson, TX 75080, USA, phone: +1 972-883-5871, e-mail: simon.siegenthaler@utdallas.edu. 


\section{Introduction}

Informational asymmetries leading to adverse selection are a persistent problem in many markets and have been studied extensively in economics since Kenneth Arrow's (1963) seminal work. Labor markets are a particularly prominent and important example where informational asymmetries lead to adverse selection and thus inefficient outcomes (Akerlof, 1970). It is therefore important to identify mechanisms that can help mitigate inefficiency in such environments. Recently, employee referrals have been identified as one such potential mechanism.

Indeed, it has been found that firms frequently fill their job vacancies through the social networks of their employees. Up to one half of all open positions in the U.S. and European labor market are allocated through referrals by friends and relatives (e.g. Ioannides and Loury, 2004; Jackson, 2010a; Pellizzari, 2010; Topa, 2011). Employee referrals are also widely used in developing countries (e.g. Heath, 2018), in migrant communities (e.g. Munshi, 2003; Beaman, 2011), and are pervasive in different industries ranging from call-centers to high-tech (e.g. Burks et al., 2015). Field empirical work has shown that referred employees benefit firms through lower turnover and lower recruitment costs. There is also some evidence that employees recruited via referrals are more likely to accept offers and earn higer wages (e.g., Burks et al., 2015; Brown et al., 2016). ${ }^{1}$

These field observations suggest that hiring through referrals entails an informational advantage in comparison to hiring on a competitive market. The general argument why this may hold is based on the idea that people tend to mainly interact with others who are like themselves, also known as homophily (e.g. McPherson et al., 2001; Currarini et al., 2009; Jackson, 2010b). In relation to employee referrals this implies that current employees tend to refer individuals of similar ability (e.g. Rees, 1966; Granovetter, 1985, 1995). If this holds, firms have an incentive to search for new workers through the social networks of their current, high-performing employees. However, to the best of our knowledge there is no direct evidence on either that firms indeed behave that way or that hiring through employee referrals causally alleviates adverse selection in labor markets.

In this paper we examine theoretically and with laboratory experiments three key questions related to hiring via referrals when potential employees have private information about their productivity. First, do employers indeed use employee referrals when there are social ties between a current employee and a future employee? Second, does the existence of social ties and hiring through employee referrals alleviate adverse selection relative to when social ties do not exist? Third, does the existence of social ties have spill-over effects on wages and hiring in competitive labor markets? In brief, the answers to all three questions are affirmative.

\footnotetext{
${ }^{1}$ We note that the use of referrals is not limited to the labor market. In markets for goods and services referrals can take the form of recommendations, e.g. when people refer doctors to their friends or when informing others about trustworthy dealers in second-hand markets.
} 
The use of laboratory experiments allows us to study the causal effect of introducing social ties and the ability of making referral offers. In the field it is difficult to identify such a causal effect because social ties are endogenous. It also allows us to examine the information value of job referrals while controlling for other potential benefits of referrals such as faster and cheaper jobmatching (e.g. Calvó-Armengol and Zenou, 2005; Galenianos, 2014). Additionally, the strength of a social tie is difficult to quantify in the field, while the experiment gives us full control over it, and we can tightly control the productivity of employees which circumvents methodological difficulties related to the estimation of productivity. In our experiments we can thus identify the fundamental drivers of behavior in a clean way. At the same time, it may be argued that behavior in a laboratory labor market is not necessarily representative for behavior in the field. ${ }^{2}$ Our study should, thus, be viewed as providing complementary evidence to the mentioned field empirical studies.

In our experiment, workers can be of a high or a low productivity type and these types are private information. There are 50\% high types and 50\% low types. Hiring takes place in two stages with a different set of workers being active in each stage. Firms seek to hire one worker per stage and after a worker is hired firms learn the productivity of that worker. In the Baseline treatment, there are no social ties between workers. In both stages, the hiring process takes place in a public competitive market where firms can freely post offers and workers choose if and when to accept. In the Referral treatment, social ties are introduced between workers who are active in stage 1 and workers who are active in stage 2 . Each stage 2 worker has a social tie with one stage 1 worker and having a social tie implies that the linked workers are of the same productivity type with a probability of $75 \%$. This mimics the idea of homophily introduced above. ${ }^{3}$ In this treatment, the hiring process in stage 1 takes place on a public competitive market as in the Baseline treatment. However, in stage 2 firms can also make referral offers. That is, they can circumvent the competitive market and make wage offers directly to the stage 2 worker who has a social tie to the previously hired stage 1 worker.

We develop a theoretical model which delivers testable hypotheses related to the three key questions introduced above. First, firms are predicted to make referral offers and such offers are more likely after having hired a high productivity worker in stage 1. Second, the existence of social ties and the use of referral offers increases the proportion of high productivity hires relative to the Baseline treatment. Third, despite the fact that referral offers are possible only in stage 2, firms increase their wage in the competitive market of stage 1, in order to attract high productivity workers and get access to higher quality social ties. In addition, the model also makes predictions on how these effects are related to agents' risk aversion.

\footnotetext{
${ }^{2}$ For a critical view on the ecological validity of laboratory experiments, see, e.g., Levitt and List (2007). Recently, however, a number of studies showed that behavior in the laboratory has predictive power for field behavior (e.g., Falk et al., 2013; Cooper and Kagel, 2016; Riedl and Smeets, 2017).

${ }^{3}$ This assumption is based on a number of empirical studies finding that employee referrals indeed convey information about the quality of the referred workers (e.g. Schmutte, 2014; Pallais and Sands, 2016; Hensvik and Skans, 2016; Dustmann et al., 2015) and that this information may be noisy (Beaman and Magruder, 2012; Fafchamps and Moradi, 2015).
} 
All three hypotheses are supported by the data. In the Referral treatment hires through referrals are common and, in comparison to the Baseline treatment, inefficiencies arising from the informational asymmetries are indeed alleviated. The positive effect of social ties is observed in both hiring stages. However, overall allocation efficiency in both treatments fall short of the efficient (second-best) outcome. We show that this is caused by a combination of risk aversion and the dynamics of the hiring process. In the public competitive markets, firms almost always start with low offers leading to low productivity hires, while the more risky strategy of raising wages above the high productivity workers' reservation wage is adopted only late during market opening time. This leads to predominantly low productivity hires and, thus, low efficiency levels.

Next to the field empirical studies discussed above our study is also related to the theoretical literature on social networks in the labor market. Theoretical models investigate job-search through personal contacts (e.g. Mortensen and Vishwanath, 1994; Pissarides, 2000; Topa, 2001; Kugler, 2003), network structure and how outcomes depend on an individual's position in a network (e.g. Boorman, 1975; Zenou, 2013), investment in new network connections to access information about available jobs (e.g., Calvó-Armengol, 2004; Galeotti and Merlino, 2014), job tenure (e.g. Loury, 2006), and how networks perpetuate inequality (e.g. Montgomery, 1991b; Calvo-Armengol and Jackson, 2004). The theoretical idea that is closest to our set-up is Montgomery (1991a) who presents a model explaining why workers who are well-connected fare better than other workers and why firms hiring through referrals tend to earn higher profits. Montgomery assumes that firms are restricted to make a single offer. We develop our own model to better capture the key features of the experimental environment where firms can make multiple wage offers over time. ${ }^{4}$

Our study also contributes to the experimental literature on adverse selection. For instance, Kübler et al. (2008) study Spence's education game, Hoppe and Schmitz (2015) examine an adverse selection model where the uninformed party can offer suitable menus of contracts to achieve separation between the different types of the informed party, and Mimra and Waibel (2017) vary the degree of market power of the uninformed party, ranging from monopoly to nonexclusive competition. A common finding in this literature is that the degree of equilibrium play tends to be high. Siegenthaler (2017) shows that cheap-talk can help alleviate adverse selection in decentralized markets and Bochet and Siegenthaler (2018) examine whether adverse selection can be mitigated through screening in bargaining environments but find that take-it-or-leave-it environments outperform environments with repeated offers. To the best of our knowledge, the present paper is the first experiment studying whether social networks can help promote welfare in markets with adverse selection. ${ }^{5}$

\footnotetext{
${ }^{4}$ Moreover, in Montgomery (1991a) there is free entry by firms and thus firms earn zero profits. In our model (as in the experiment), there are fewer firms than workers, implying that firms have some market power. However, because workers' types are private information, workers can also extract some of the surplus.

${ }^{5}$ Other experimental studies have focused on moral hazard in labor market settings. Fehr et al. (1993) and Fehr et al. (1997), in line with Akerlof $(1982,1984)$, developed the gift exchange game to capture contractual
} 
The paper proceeds as follows. In Section 2 we present the experimental design, Section 3 introduces the theoretical model and derives three key hypotheses, and in Section 4 we present the experimental results. Section 5 concludes.

\section{The Experiment}

The experiment consists of two treatments. In the Baseline treatment there are no social ties among workers and firms hire workers in anonymous public posted-offer markets. In the Referral treatment social networks are introduced such that each worker has a social tie with one other worker and firms may hire workers through referrals. The treatments are described in more detail below. First we present the general setting that applies to both treatments.

\subsection{General Setting}

At the beginning of an experiment session, each of the 16 participants is randomly assigned the role of either a firm or a worker. These roles remain fixed throughout the experiment. The experiment consists of 15 periods and firms and workers interact in a two-stages labor market in each period. In each market there are 4 firms and 12 workers. The composition of firms and workers in a market is the same throughout the 15 periods. In a period, in each stage firms seek to hire at most one worker and each hiring stage lasts for 2 minutes. Firms are active in both stages whereas the 12 workers are divided in 6 stage- 1 workers and 6 stage- 2 workers. A stage- 1 worker is only active in stage- 1 and can thus only be hired in stage-1; equivalently for stage- 2 workers. Whether a worker is active in stage 1 or stage 2 is randomly determined at the beginning of each period.

Workers are further divided into low-productivity (L-type) and high-productivity (H-type) workers. Specifically, in each hiring stage there are 3 L-type and 3 H-type workers. The productivity of a worker is randomly determined at the beginning of each period. Importantly, firms know the distribution of worker types but learn a worker's actual productivity only after the worker is hired.

In the experiment, the set of possible wage offers is $\{0,1, \ldots, 59,60\}$. A low productivity worker produces an output $P_{L}=20$ and a high productivity worker produces an output of $P_{H}=60$. If a firm pays a wage $w$ her payoff in a given stage is

incompleteness in labor markets. They show that reciprocal fairness may overcome moral hazard. Brown et al. (2004) show that successful long-term relationships can lead to high effort levels and wage offers. Andreoni (2017) finds that selling goods with a "satisfaction guarantee" helps mitigate problems of moral hazard. 


$$
\pi_{F}(\theta, w)= \begin{cases}P_{\theta}-w+20 & \text { if a worker of type } \theta=\{L, H\} \text { is hired } \\ 0 & \text { if no worker is hired, }\end{cases}
$$

where the added 20 can be interpreted as a baseline productivity that is independent of the hired worker's type. ${ }^{6}$ The total payoff of a firm per period equals the sum of payoffs in stages 1 and 2 .

Workers of different productivity type have different reservation wages. An L-type worker has a reservation wage of $\lambda_{L}=10$ and an $\mathrm{H}$-type worker has a reservation wage of $\lambda_{H}=30$. The payoff of a worker is

$$
\pi_{W}(\theta, w)= \begin{cases}w & \text { if hired } \\ \lambda_{\theta} & \text { if not hired and of type } \theta=\{L, H\} .\end{cases}
$$

Note that the different reservation wages make it risky for firms to try to hire a high productivity worker. Hiring such a worker requires a wage offer of at least 30, which, however, would lead to a low payoff in case a low productivity worker accepts the offer. ${ }^{7}$

\subsection{Treatments}

The two treatments differ in two aspects. First, in how the productivity of stage-1 workers is related to the productivity of stage- 2 workers, and second, in whether hiring workers via referrals is possible or not. Here we describe the two treatments and their differences in detail.

Baseline treatment. In this treatment, the productivity of any given stage- 1 worker is independent of the productivity of any given stage- 2 worker. In both hiring stages, firms make wage offers in a public and anonymous posted-offer market. We will refer to such offers as public offers. All firms and all workers active in a stage can observe all public offers. Workers not active in a stage do not observe any offers. Firms are free when or how many offers they would like to make and workers can accept any of the standing offers at any time. A worker who accepts an offer is hired at the corresponding wage by the firm which made the offer and this worker-firm pair leaves the market. The remaining workers can still get hired by the other firms on the market.

When making offers, firms have to abide by the improvement rule. That is, every new wage offer has to be higher than the currently highest standing wage offer. In case there are no more

\footnotetext{
${ }^{6}$ The baseline productivity of 20 minimizes the risk of negative payoffs in the experiment. As we will see later, it guarantees firms a positive payoff when hiring an L-type worker at the H-type workers' reservation wage. Still, in the theoretical model we present below, equilibrium market wages can be below the H-type workers' reservation wage, which gives rise to adverse selection.

${ }^{7}$ To keep payoffs between firms and workers comparable, in the experiment workers received a payoff in both stages. In the stage in which they were not active they received the reservation wage.
} 
standing offers (because each offer has been accepted by a worker), offers can again start at 0 . In both stages, the market is open for at most 2 minutes or until all firms have hired a worker.

Referral treatment. In this treatment, social ties link the productivity of stage- 1 workers to the productivity of stage-2 workers, such that two linked workers are of the same type with probability 0.75. Social ties are randomly assigned among workers at the beginning of each trading period and each stage- 1 worker is uniquely linked to exactly one stage- 2 worker.

In this treatment the first stage is exactly the same as in the Baseline treatment and all trading takes place via public offers. However, social ties affect the hiring opportunities of firms in the stage-2 market. Specifically, firms can make two types of offers. First, they can still make public offers which are observed by all firms and workers active on the market. Second, they can try to hire a worker through an offer that is only received and observed by the stage- 2 worker who has a social tie with the respective firm's stage-1 worker. We will refer to such offers as referral offers. Firms can make multiple offers of both types (public and referral offers) and these offers can be made simultaneously. In stage 2 , public offers have to abide by the improvement rule and referral offers can be changed in any way.

In the experiment firms and workers in stage 2 of the Referral treatment see two panels with offers. In one panel, firms can make and workers can accept public offers just like in stage 1, and in the other panel firms can make and workers accept private referral offers. A screen shot of the experimental interface can be found in the Online Appendix.

\subsection{Information}

In both treatments, participants know all the parameters of the experiment. That is, they know that there are 15 periods with two trading stages in each period, that there are 4 firms and 6 workers per trading stage, that among the 6 workers there are 3 low and 3 high productivity types, and what the payoff functions of both firms and workers are. In the Referral treatment, everyone knows at the start of the experiment that stage- 1 and stage- 2 workers who are linked by a social tie are of the same productivity type with a chance of $75 \%$. Finally, firms and workers active in a stage can observe all public offers made in that stage. Any referral offer can only be seen by the worker who receives the offer.

\subsection{Procedures}

The computerized experiment was run in the BEElab at Maastricht University, using experiment software z-Tree (Fischbacher, 2007) and participants were recruited from the BEElab participant pool via ORSEE (Greiner, 2015). In total 11 sessions were conducted of which 5 for treatment Baseline and 6 for treatment Referral. Each session consisted of 16 participants (4 firms and 12 
workers). The total number of participants was 176. At the beginning of a session each participant was randomly assigned to a closed cubicle where they made decisions in private. The experiment instructions included a set of control questions to check participants' understanding. The instructions can be found in Online Appendix D. Sessions lasted 100 minutes or less. Payments averaged 19 Euros per participant including a show up fee of 5 Euros. $^{8}$

\section{Theoretical Background and Hypotheses}

This section derives a set of hypotheses for each experimental treatment. We base the predictions on a model which we believe captures well the basic features of the experimental game described above.

\subsection{Model}

Consider a market with $n_{F}$ firms, $n_{L}$ low productivity workers and $n_{H}$ high productivity workers. Workers' types are private information. We assume $P_{H}-\lambda_{H}>P_{L}-\lambda_{L}$, i.e. the gains from trade are larger with H-type workers. There are two stages and each firm can hire at most one worker per stage. In each stage the market opens with firms announcing a finite number of wages. Workers then choose the wage offers they would like to accept. A worker can accept none, one, or several of the offers made by the firms. Given these decisions, firms and workers are then matched from low to high wages. In particular, market clearing starts at the lowest accepted wage offer, say $w_{1}$. Among the workers who chose to accept $w_{1}$, one is hired at random. Then, the next highest accepted wage offer $w_{2}$ is selected resulting in another firm-worker match. This process continues until all firms hired a worker or the highest accepted wage offer is reached..$^{9,10}$

We allow for risk aversion and assume that an agent's utility is given by

$$
u(\pi)=1-e^{-\sigma \pi}
$$

\footnotetext{
${ }^{8}$ Typical for adverse selection settings, in our experiment it is possible that participants receive negative payoffs. This could be problematic if a participant goes bankrupt, which most likely happens in early periods when participants haven't accrued profits yet. To counter this, participants received an additional endowment of 120 experimental points (conversion rate: 1 point $=0.0225$ Euro cent). No participant went bankrupt.

${ }^{9}$ This procedure is in line with the experimental setting where wages have to follow an improvement rule. However, the model does not mirror the experimental setting exactly. In the experiment the bargaining process is dynamic and wage offers and acceptances occur dynamically. In the experiment, this allows us to mimic a realistic scenario where firms and workers can respond to what they observe in the market. For reasons of tractability, in the model we assume that firms first choose a set of wage offers and only then workers choose which wages to accept.

${ }^{10}$ The model is inspired by Wilson (1980) who studies markets with adverse selection under different price setting conventions, including the one where firms make wage offers. Wilson assumes that market clearing starts at the highest wage and each firm can only make a single wage offer.
} 
where $\pi$ represents the payoffs defined in (1) and (2) and $\sigma>0$ measures the degree of absolute risk aversion. ${ }^{11}$

\subsection{Market Equilibrium in Baseline}

A market equilibrium is reached if firms' wage offers and workers acceptance decisions maximize their respective expected utilities, given everyone else's behavior, and firms' beliefs about the expected quality of workers are correct at all wage levels. ${ }^{12}$ In the following, we focus on the key predictions and refer to the appendix for a detailed analysis.

Recall that in the Baseline treatment stages 1 and 2 are identical and that there are no social ties. Equilibria take the following form. Firms randomize between posting the H-type reservation wage $\left\{\lambda_{H}\right\}$ or the set of wages $\left\{w^{*}, \lambda_{H}\right\}$, where $w^{*}$ is such that $\lambda_{L}<w^{*}<\lambda_{H}$ and depends on the specific equilibrium as well as on risk aversion. ${ }^{13}$ The trade-off between $\left\{\lambda_{H}\right\}$ and $\left\{w^{*}, \lambda_{H}\right\}$ is apparent: hiring an H-type worker at a wage of $\lambda_{H}$ generates large gains from trade but involves the risk of hiring an L-type worker in which case the wage $w^{*}$ would have been preferable. H-type workers only accept high wages. L-type workers accept both wages $w^{*}$ and $\lambda_{H}$. The reason they accept $w^{*}$ is that at a wage of $\lambda_{H}$ they face competition from H-type workers, i.e. some workers will remain unemployed. Notice that this explains why it is always optimal for a firm that offers $w^{*}$ to also include offer $\lambda_{H}$ in its wage schedule: Because $w^{*}$ is accepted by L-type workers and market clearing occurs from low to high wages, at equilibrium a firm that offers $\left\{w^{*}, \lambda_{H}\right\}$ will hire at a wage of $\lambda_{H}$ only if all L-type workers have already left the market (in other words, including wage offer $w^{*}$ in the set of offered wages guarantees a positive payoff).

Figure 1 illustrates the market equilibrium in dependence of agents' risk aversion for the experimental parameters. The left panel (a) shows the average accepted offer and the right panel (b) the percentage of high productivity workers among all hired workers, where the total number of hires is four (thus, in equilibrium each firm hires a worker). The solid lines depict the predictions for treatment Baseline. Notice that for low levels of risk aversion the equilibrium wage equals

\footnotetext{
${ }^{11}$ We assume that risk preferences are identical across agents. The model can easily accommodate situations in which firms and workers have different risk preferences (as long as risk preferences are the same for all agents on a given market side). In Online Appendix C, we discuss the case of risk-neutral employers/firms, which is relevant from an empirical perspective where firms are often thought to be less risk averse than individual workers. The main effect is that competition between firms for high productivity workers is stronger, as firms are less concerned about the downside of hiring a low productivity worker at a high wage. Interestingly, however, even when all wage offers match the high productivity workers' reservation wage, referral offers still improve the average quality hired in stage 2 of the market, because firms which hired a high productivity stage- 1 worker still want to use the social tie of the worker to increase their chance at hiring another high productivity worker in stage 2 .

${ }^{12}$ Beliefs are required to be correct also at wages that are not offered in equilibrium. That is, we are interested in equilibrium outcomes that are robust to firms and workers experimenting with different off-equilibrium strategies (see Wilson, 1980; Mas-Colell et al., 1995).

${ }^{13}$ Notice that we assume $n_{L}+n_{H} \geq n_{F}>n_{L}$, as in the experiment. If $n_{F} \leq n_{L}$ firms are essentially monopsonists and offer either $\left\{\lambda_{L}\right\}$ or $\left\{\lambda_{H}\right\}$. If $n_{F}>n_{L}+n_{H}$, competition between firms drives offers above $\lambda_{H}$ such that firms' expected profit is zero.
} 


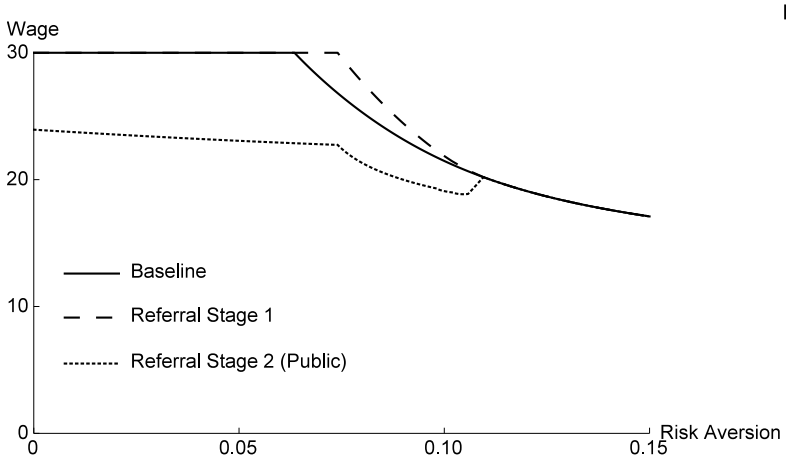

(a) Average Wage in Public Market

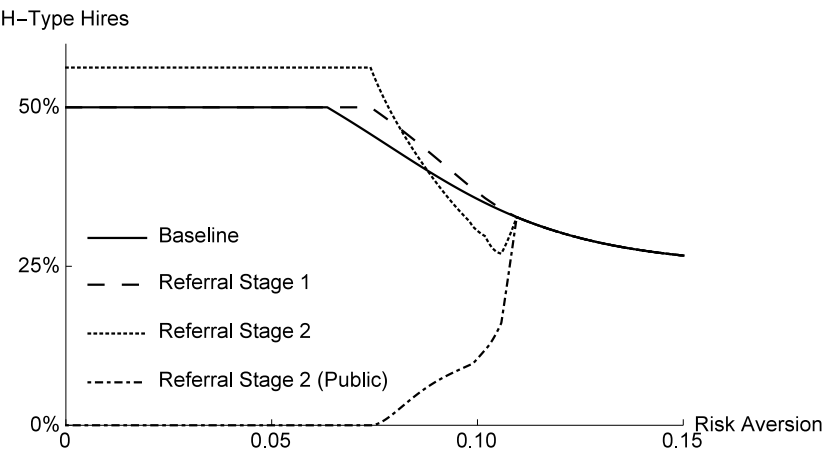

(b) Percentage of H-Type Hires

Figure 1: Equilibrium Outcomes

Notes: Theoretical predictions for the experimental parameters $n_{F}=4, n_{L}=n_{H}=3, P_{L}=20, P_{H}=60, \lambda_{L}=10$, $\lambda_{H}=30, B=20$ (added productivity parameter), and different levels of risk aversion. Panel (a): average accepted wage offers in public market. Panel (b): percentage of H-type workers among all hires where the total number of hired workers equals 4 . For stage 2 of the Referral treatment the dotted line shows the percentage of H-type workers hired combined for public and referral offers; the dash-dotted line shows the corresponding percentage for the public market only.

$\lambda_{H}=30$ and the percentage of hired H-type workers is $50 \%$. All six workers accept a wage of 30 and on average two workers of each productivity type get hired. As agents become more risk averse firms start randomizing between $\left\{w^{*}, \lambda_{H}\right\}$ and $\left\{\lambda_{H}\right\}$ exerting downward pressure on the average wage level. Two effects are at play: first, firms become more reluctant to make high offers and second, L-type workers' willingness to accept low wages increases. The latter happens because the risk of not getting hired plays a larger role in L-type workers' utility calculations. As a result of the lower wage, the percentage of hired H-type workers falls towards $25 \%$ for higher levels of risk aversion implying a stronger adverse selection effect. This implies an ex-post social welfare loss, because from a social welfare perspective as many H-type workers as possible should be hired, as the gains from trade with an H-type equal $60-30=30$ while for an L-type they are only $20-10=10 .{ }^{14}$

\subsection{Market Equilibrium in Referral}

We next discuss whether the possibility to make referral offers alleviates adverse selection. In stage 1 of the Referral treatment, the hiring process happens in a public market, as in the Baseline treatment. In stage 2, firms can still hire in the public market but, importantly, they can also hire through referral offers using the social ties of the hired period-1 worker. Recall, that

\footnotetext{
${ }^{14}$ In Online Appendix A we show that the Walrasian equilibrium outcome exhibits inefficiencies similar to the equilibrium of our model. In the Walrasian equilibrium three L-type workers and one H-type worker are hired, while efficiency requires three H-type hires and one L-type hire.
} 
the linked stage- 2 worker is of the same productivity type as the stage- 1 worker with a chance of $75 \%$.

The dashed lines in Figure 1 depict the equilibrium outcomes in stage 1 of the Referral treatment. We can see that for some range of risk aversion average wages are higher in stage 1 of treatment Referral than in Baseline. Firms are willing to make these higher offers in Referral because hiring an H-type worker has the additional benefit of providing access to a valuable social tie that can be used in stage 2. As a result, more H-type workers are hired.

In equilibrium, in stage 2 of the Referral treatment, up to a risk coefficient of about 0.1 , firms that have hired an H-type worker in stage 1 always make referral offers of 30 in stage 2 . For higher levels of risk aversion, there is a sharp decrease in the use of social ties until the difference between the treatments disappears. Then, even a $75 \%$ probability of hiring an H-type worker is too risky and firms focus on hiring L-type workers in the public market. Correspondingly, we can see in Figure 1(b) that the percentage of H-type hires is higher in the Referral treatment as long as the degree of risk aversion is not too large (dotted line). Later we will see that the risk coefficient for firms in our experiment is around 0.05 , which is in the range where the possibility of making referral offers promotes hires of H-type workers. ${ }^{15}$

We summarize the discussion of the theoretical model in the following hypotheses:

Hypothesis 1 (Public Market Wages): Wages in the stage-1 public market tend to be higher in Referral than in Baseline. In contrast, wages in the stage-2 public market tend to be lower in Referral than in Baseline.

Hypothesis 2 (Referral Offers): In stage 2, firms are more likely to use referral offers if, in stage 1, they hired an H-type in comparison to when they hired an L-type worker. Referral offers are equal to the H-type workers' reservation wage of 30 .

Hypothesis 3 (Hires): The percentage of H-type hires is higher in Referral than in Baseline. This holds in both stages.

Recall that Hypothesis 3 holds because in the Referral treatment hiring an H-type worker in stage 1 provides access to a social tie, which can then be used to hire an H-type worker in stage 2 with a high probability. Hence, social ties are predicted to increase the percentage of H-type hires in both stages.

\footnotetext{
${ }^{15}$ Referral hires tend to reduce the number of H-type workers active in the public market and hence also the willingness of firms to make high public offers. This is illustrated in Figure 1(a) showing lower average wages in the public market of stage-2 in the Referral treatment. Due to this effect, as shown in Figure 1(b), the availability of referral offers reduces the overall percentage of H-type hires for some higher values of risk aversion.
} 

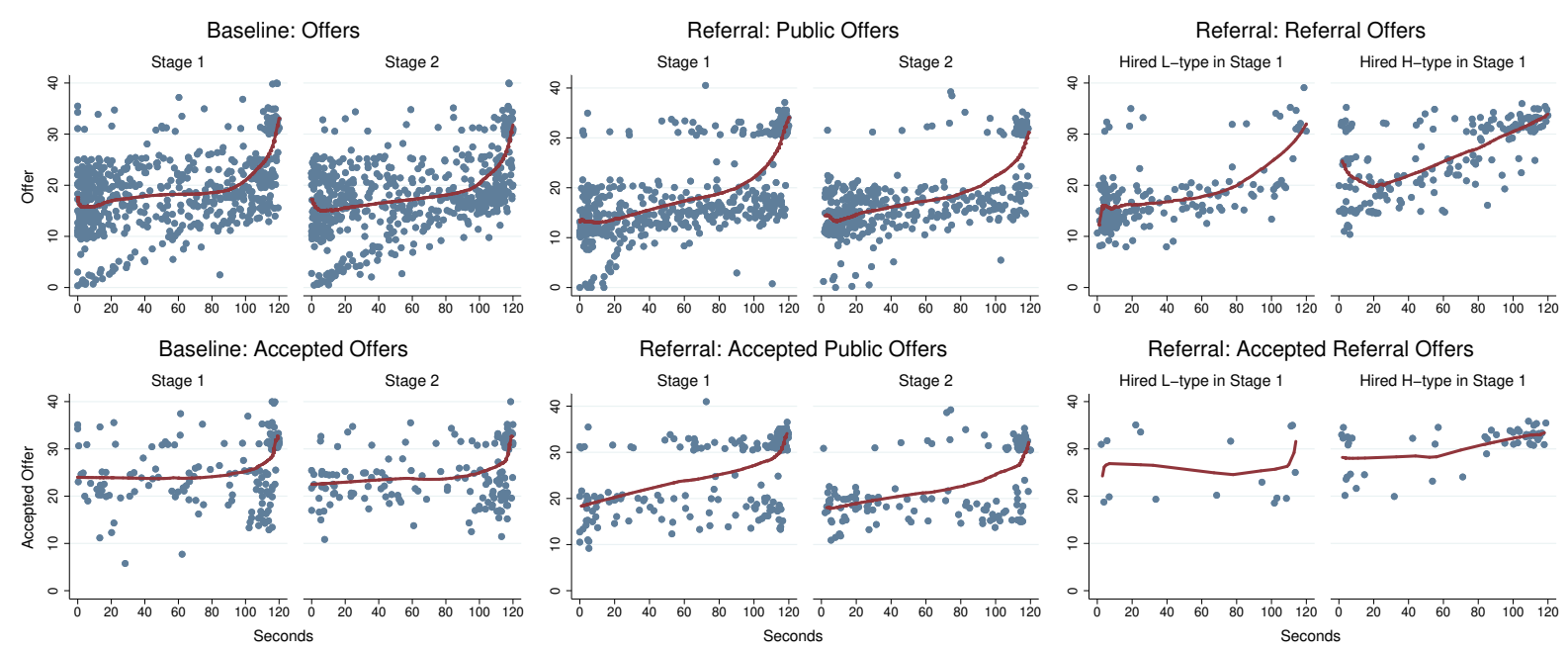

Figure 2: Wage Offers and Accepted Wages

Notes: The first row shows all offers (accepted or not) over time within a trading stage by treatment, stage and public versus referral offers in Referral. The second row shows accepted offers (wages). Graphs include smoothed values from locally weighted regressions.

\section{Results}

We will first discuss offers and accepted wages in Section 4.1, then examine hires and efficiency in Section 4.2, and finally take a more detailed look at the strategies adopted on the individual level and the role of risk aversion in Section 4.3. Recall that the experiment consisted of 15 periods with a stage- 1 and a stage- 2 market in each period. In the following we focus on the final 10 periods (periods 6 - 15) to account for learning effects and behavior is more stable than in earlier periods. ${ }^{16}$

\subsection{Offers and Wages}

We start with a general look at firms' wage offers over the 120 seconds a market stage was (maximally) open. Figure 2 conveys the general pattern in wages offered and accepted. The first row in the figure shows all offers in the two treatments and both stages. There is a clear pattern visible which we summarize in the following result.

Result 1. In the public markets of both treatments firms appear to engage in screening behavior. They start by offering wages that are clearly below 30, and thus target L-type workers. Only towards the end of a trading stage, wage offers increase to the H-type workers' reservation wage of 30 and above.

\footnotetext{
${ }^{16}$ In Online Appendix C.1 we show that the differences in behavior between Baseline and Referral are stable over time and become more pronounced in later periods.
} 
Table 1: Summary of Wage Offers, Accepted Wages, Hires and Efficieny

\begin{tabular}{|c|c|c|c|c|c|c|c|c|c|c|c|c|}
\hline \multirow{3}{*}{$\begin{array}{l}\text { Treatment: } \\
\text { Type }\end{array}$} & \multicolumn{4}{|c|}{ Baseline } & \multicolumn{8}{|c|}{ Referral } \\
\hline & \multicolumn{2}{|c|}{ Stage 1} & \multicolumn{2}{|c|}{ Stage 2} & \multicolumn{2}{|c|}{ Stage 1} & \multicolumn{2}{|c|}{$\begin{array}{l}\text { Stage } 2 \\
\text { Overall }\end{array}$} & \multicolumn{2}{|c|}{$\begin{array}{c}\text { Stage } 2 \\
\text { Public Offers }\end{array}$} & \multicolumn{2}{|c|}{$\begin{array}{c}\text { Stage } 2 \\
\text { Referral Offers }\end{array}$} \\
\hline & $\mathrm{H}$ & $\mathrm{L}$ & $\mathrm{H}$ & $\mathrm{L}$ & $\mathrm{H}$ & $\mathrm{L}$ & $\mathrm{H}$ & $\mathrm{L}$ & $\mathrm{H}$ & $\mathrm{L}$ & $\mathrm{H}$ & $\mathrm{L}$ \\
\hline Offers & \multicolumn{2}{|c|}{19.3} & \multicolumn{2}{|c|}{19.3} & \multicolumn{2}{|c|}{19.1} & \multicolumn{2}{|c|}{19.6} & \multicolumn{2}{|c|}{17.8} & \multicolumn{2}{|c|}{21.5} \\
\hline Offers $\geq 30$ & \multicolumn{2}{|c|}{$14 \%$} & \multicolumn{2}{|c|}{$13 \%$} & \multicolumn{2}{|c|}{$26 \%$} & \multicolumn{2}{|c|}{$21 \%$} & \multicolumn{2}{|c|}{$16 \%$} & \multicolumn{2}{|c|}{$26 \%$} \\
\hline Wages & 30.9 & 24.3 & 31.4 & 23.6 & 31.1 & 24.0 & 32.0 & 21.6 & 31.2 & 20.8 & 32.6 & 25.3 \\
\hline Wages $\geq 30$ & $88 \%$ & $30 \%$ & $92 \%$ & $23 \%$ & $92 \%$ & $44 \%$ & $95 \%$ & $23 \%$ & $92 \%$ & $22 \%$ & $100 \%$ & $28 \%$ \\
\hline Hires (No.) & 0.9 & 2.7 & 0.8 & 2.8 & 1.3 & 2.4 & 1.3 & 2.4 & 0.6 & 2 & 0.7 & 0.4 \\
\hline Hires $(\%)$ & $25 \%$ & $75 \%$ & $22 \%$ & $78 \%$ & $35 \%$ & $65 \%$ & $34 \%$ & $66 \%$ & $23 \%$ & $77 \%$ & $61 \%$ & $39 \%$ \\
\hline Efficiency & \multicolumn{2}{|c|}{$53 \%$} & \multicolumn{2}{|c|}{$52 \%$} & \multicolumn{2}{|c|}{$63 \%$} & \multicolumn{2}{|c|}{$62 \%$} & \multicolumn{2}{|c|}{ - } & \multicolumn{2}{|c|}{ - } \\
\hline
\end{tabular}

Notes: Data from periods $\geq 6$. "H" ("L") stands for H-(L-)type worker. Variables by row: average offers; \% of offers equal to or above 30; average wages (accepted offers) of $\mathrm{H}$ and L, respectively; \% of wages (accepted offers) equal to above 30 of $\mathrm{H}$ and L, respectively; average number of $\mathrm{H}$ and $\mathrm{L}$ hired; $\%$ of $\mathrm{H}$ and $\mathrm{L}$ hired; efficiency levels as $\%$ of realized gains from trade relative to the first-best outcome where three H-type and one L-type workers are hired.

The lower panels of Figure 2 show accepted wage offers (i.e., hires) and provides two eye-catching observations. First, acceptances occur throughout the whole 120 seconds a stage is open and (presumably) L-type workers accept offers below 30. Second, there is a concentration of hires towards the end of the trading stage, mainly around the last 20 seconds. After these first visual impressions we now provide a quantitative analysis of offers and wages, starting with the behavior in stage 1. We first present results followed by empirical support.

Result 2. In stage 1, firms in the Referral treatment are more likely to offer wages at or above 30 than firms in the Baseline treatment. Consistent with this, the percentage of L-type workers receiving a wage equal to or above 30 is higher in the Referral treatment than in the Baseline treatment.

Table 1 provides an overview of average wage offers, accepted wage offers, frequency of hires of $\mathrm{H}$ - and L-type workers, and achieved efficiency levels. The second row of the table presents the percentage of offers equal to or above 30, which in stage 1 is higher in Referral than in Baseline (26\% versus $14 \%$, Mann-Whitney U, $p=0.017) .{ }^{17}$ Consistent with this, the median accepted wage in Referral is 31, while it is only 25 in Baseline (Mann-Whitney $\mathrm{U}, p=0.039$ ). This difference in stage 1 wage offers between treatments is corroborated by random effects regression analyses presented in Table 2, which also provide insights into the timing of offers. In models (1) and (2), the dependent variable is the percentage of offers equal to or above 30 in stage 1 . The explanatory variables are a dummy for the Referral treatment and-in model (2) - a dummy Late equaling one for offers made in the second half of the market opening time (i.e., after 60 seconds) as well as an interaction between the treatment and the timing of the offer.

\footnotetext{
${ }^{17}$ All non-parametric tests use session averages as unit of observation with 5 observations in Baseline and 6 observations in Referral.
} 
Table 2: Regression Analysis of Offers and Wages

\begin{tabular}{|c|c|c|c|c|c|c|c|c|}
\hline \multirow{3}{*}{ Dep. Var: } & \multicolumn{4}{|c|}{ Stage 1} & \multicolumn{4}{|c|}{ Stage 2} \\
\hline & \multicolumn{2}{|c|}{ Offer $\geq 30$} & \multicolumn{2}{|c|}{ L-type Wage $\geq 30$} & \multicolumn{2}{|c|}{ Offer $\geq 30$} & \multicolumn{2}{|c|}{ L-type Wage $\geq 30$} \\
\hline & (1) & $(2)$ & $(3)$ & $(4)$ & $(5)$ & $(6)$ & $(7)$ & $(8)$ \\
\hline Referral & $\begin{array}{c}0.12^{* * *} \\
(0.03)\end{array}$ & $\begin{array}{c}0.00 \\
(0.03)\end{array}$ & $\begin{array}{l}0.13^{*} \\
(0.07)\end{array}$ & $\begin{array}{l}-0.04 \\
(0.16)\end{array}$ & $\begin{array}{c}0.08 * * * \\
(0.02)\end{array}$ & $\begin{array}{c}0.03 \\
(0.02)\end{array}$ & $\begin{array}{l}-0.01 \\
(0.07)\end{array}$ & $\begin{array}{l}-0.04 \\
(0.05)\end{array}$ \\
\hline Late $(>60 \mathrm{sec})$ & & $\begin{array}{c}0.22^{* * *} \\
(0.06)\end{array}$ & & $\begin{array}{c}0.17 \\
(0.16)\end{array}$ & & $\begin{array}{c}0.21^{* * *} \\
(0.05)\end{array}$ & & $\begin{array}{c}0.23^{* * *} \\
(0.04)\end{array}$ \\
\hline Referral $\times$ Late & & $\begin{array}{c}0.22^{* * *} \\
(0.08)\end{array}$ & & $\begin{array}{c}0.28 \\
(0.19)\end{array}$ & & $\begin{array}{c}0.19 * * * \\
(0.06)\end{array}$ & & $\begin{array}{c}0.10 \\
(0.10)\end{array}$ \\
\hline Constant & $\begin{array}{c}0.01 \\
(0.04)\end{array}$ & $\begin{array}{c}0.06^{* *} \\
(0.28)\end{array}$ & $\begin{array}{l}0.20^{*} \\
(0.12)\end{array}$ & $\begin{array}{c}0.20 \\
(0.16)\end{array}$ & $\begin{array}{c}0.03 \\
(0.03)\end{array}$ & $\begin{array}{c}0.03 \\
(0.04)\end{array}$ & $\begin{array}{c}0.18 \\
(0.15)\end{array}$ & $\begin{array}{c}0.05 \\
(0.08)\end{array}$ \\
\hline Wald Test $^{(a)}$ & & $p=0.002$ & & $p<0.001$ & & $p<0.001$ & & $p=0.511$ \\
\hline Observations & 1197 & 1197 & 277 & 277 & 1411 & 1411 & 260 & 260 \\
\hline
\end{tabular}

Notes: Linear random effects models with standard errors clustered on experimental sessions in parentheses, ${ }^{*} p<0.10,{ }^{* *} p<0.05$, *** $p<0.01$. Bootstrap standard errors yield qualitatively identical results. Period dummies included in all regressions. (a) Wald chi-squared tests for the hypothesis 'Referral + Referral $\times$ Late' $=0$. The reference group in models (1), (3), (5) and (7) is the Baseline treatment, while in the remaining models it is the first 60 seconds of a market stage in Baseline. For stage 2, regressions (5) and (6) include public and referral offers while regressions (7) and (8) only include wages in the public market.

Model (1) shows that in stage 1, offers equal to or above 30 are significantly more likely in Referral than in Baseline $(p<0.001)$ and model $(2)$ indicates that this effect is exclusively due to offers made in the second half of the market opening time (Referral + Referral $\times$ Late $=0$, Wald chi-squared test, $p=0.002)$. Consistent with these observations, the percentage of Ltype workers earning a wage equal to or above 30 is higher in Referral than in Baseline (44\% vs. $30 \%$, see row 'Wages $\geq 30$ ' in Table 1 ). To see if this difference is statistically significant, models (3) and (4) in Table 2 replicate models (1) and (2) for accepted wages of L-type workers only. Model (3) shows that the percentage of wages equal to or above 30 accepted by L-type workers is indeed (marginally) significantly higher in Referral than in Baseline $(p=0.06)$. Again this effect is mainly due to behavior in the second half of the market opening time in stage 1 $(p<0.001)$.

Given the reported differences, it seems surprising that the average offers in stage 1 are similar in the two treatments (see row 'Offers' in Table 1). To understand this, we refer to Figure 2. There, it can be seen from the stage 1 panels 'Baseline: Offers' and 'Referral: Public Offers' (left and middle panel in first row) that in the Baseline treatment there are almost no offers between 25 and 30 but plenty of offers between 20 and 25 , whereas in the Referral treatment there are almost no offers over the entire range of 20 to 30. Thus, despite the larger percentage of offers at and above 30 and the higher median offer in Referral, it happens that the average offers in both treatments are similar because in Baseline offers below 30 are higher than in Referral. This 
observation is entirely consistent with predictions of our model. The presence of social ties in Referral increases firms' expected profits when trying to hire H-type workers with wage offers of at least 30. To compensate for the higher wage costs, for firms still willing to hire L-type workers, L-type hires must occur at lower wages.

Result 3. In stage 2, average wages in the public market are lower in the Referral treatment than in the Baseline treatment. However, the percentage of L-type workers earning a wage equal to or above 30 is not significantly different between treatments.

The average public offer in stage 2 of Baseline is 19.3, while it is 17.8 in Referral (see 'Offers' in Table 1). The corresponding average wage in the public market is 25.4 in Baseline and 23.2 in Referral (Mann-Whitney U, $p=0.044$ ). Focusing only on L-type workers, from 'Wages' in Table 1 it can be seen that the average wage of 23.6 in the Baseline treatment exceeds the average wage of 20.8 of such workers hired on the public market in the Referral treatment (Mann-Whitney U, $p=0.044)$. The reason for this is that in the Referral treatment competition between L-type workers is intensified in stage- 2 public markets because some firms hire workers through referral offers and do not participate in the public market. The pressure on wages in the public stage- 2 market of treatment Referral does not imply that firms are more successful at screening L-type workers: The percentage of L-type workers hired at a wage equal to or above 30 on the public market is similar across treatments (23\% versus $22 \%$ ). Regression models (7) and (8) in Table 2 show that there is no significant difference in these percentages between treatments either overall or when focusing on the second half of the market opening time.

Overall, the results up to now show that information asymmetries lead to relatively low wages on public (competitive) markets, impeding trading opportunities for high productivity workers. Also, Results 2 and 3 largely support our Hypothesis 1 on public market wages. Specifically, the prediction that the existence of referral hiring in stage 2 gives an incentive to firms to offer high wages already in the competive stage 1 is borne out by the data. We next examine referral offers and explore if they have the predicted mitigating effect on adverse selection.

Result 4. In stage 2 of the Referral treatment, firms mainly use referral offers after they hired an H-type worker in stage 1 and most referral offers are equal to or above the H-type workers' reservation wage of 30 .

The right-most panels in Figure 2 show referral offers and accepted wages in stage 2 of the Referral treatment, split by whether the worker hired in stage 1 was of the $\mathrm{L}$ or H-type. The lower panel shows that firms which hired an L-type worker in stage 1 only rarely hire workers through referral offers. In contrast, there are much more referral hires of firms which hired an H-type worker in stage 1 and a large majority of them are hired at wages equal to or slightly above 30. Consistent with this, Table 1 shows that referral offers tend to be higher than public offers in stage 2 of the Referral treatment as well as the Baseline treatment (21.5 versus 17.8 and 19.3 , respectively). 
Table 3: Referral Treatment-Likelihood of Referral Offers, Offer Levels, and Likelihood of H-type Hires in Stage 2

\begin{tabular}{|c|c|c|c|c|}
\hline Dep. Var. & $\begin{array}{c}(1) \\
\text { Referral Offer (Yes/No) }\end{array}$ & $\begin{array}{c}(2) \\
\text { Offer Level }\end{array}$ & $\stackrel{(3)}{\text { Offer Level } \geq 30}$ & $\begin{array}{c}(4) \\
\text { H-type Hire in Stage } 2\end{array}$ \\
\hline Hired H-type in Stage 1 & $\begin{array}{c}0.353^{* * *} \\
(0.0595)\end{array}$ & $\begin{array}{c}0.235 \\
(1.291)\end{array}$ & $\begin{array}{c}0.0665 \\
(0.0723)\end{array}$ & $\begin{array}{c}0.157 \\
(0.124)\end{array}$ \\
\hline Referral Offer (Yes/No) & & $\begin{array}{c}0.155 \\
(0.425)\end{array}$ & $\begin{array}{l}-0.0399 \\
(0.0223)\end{array}$ & $\begin{array}{l}0.0396 \\
(0.169)\end{array}$ \\
\hline $\begin{array}{l}\text { Hired H-type in Stage } 1 \times \\
\text { Referral Offer }(\text { Yes/No) }\end{array}$ & & $\begin{array}{c}7.727^{* * *} \\
(1.128)\end{array}$ & $\begin{array}{c}0.266^{* * *} \\
(0.0611)\end{array}$ & $\begin{array}{c}0.323 \\
(0.279)\end{array}$ \\
\hline Constant & $\begin{array}{c}0.352^{* * *} \\
(0.0830)\end{array}$ & $\begin{array}{c}18.66^{* * *} \\
(0.826)\end{array}$ & $\begin{array}{c}0.179 * * * \\
(0.0445)\end{array}$ & $\begin{array}{c}0.225 \\
(0.126)\end{array}$ \\
\hline Observations & 735 & 735 & 735 & 204 \\
\hline
\end{tabular}

Notes: Linear random effects models with standard errors clustered on experiment sessions in parentheses, ${ }^{*} p<0.05$, ** $p<0.01$, *** $p<0.001$. Bootstrap standard errors yield qualitatively identical results. Dependent variables: 'Referral Offer' $=1$ if 'yes', 'Offer Level' equals offered wage level, 'Offer Level $\geq 30$ ' $=1$ if yes, 'Htype Hire in Stage 2'=1 if yes. Independent variables are all dummy variables equaling 1 if statement in table is true. Period dummies included in all regressions. For model (4), Wald chi-squared test for the hypothesis 'Hired H-type in Stage $1+$ Hired H-type in Stage $1 \times$ Referral Offer' $=0$ is rejected at $p<0.001$.

To test for statistical significance we conduct a number of random effects regressions which are reported in Table 3. Specification (1) shows that firms are 35.3 percentage points $(p<0.001)$ more likely to make referral offers when they hired an H-type worker in stage 1 . Specifications (2) and (3), respectively, show that referral offers of firms that hired an H-type in stage 1 are on average 7.72 points $(p<0.001)$ higher and 26.6 percentage points $(p<0.001)$ more likely to exceed 30 than referral offers of firms that hired an L-type worker in stage 1 . Together these results support our Hypotheses 2.

Moreover, specification (4) indicates that firms are $0.157+0.323=48$ percentage points more likely to hire an H-type worker in stage 2 if they make a referral offer and have hired an H-type worker in stage $1(p<0.001)$. Further, combining public and referral offers, in the Referral treatment, firms are more likely to offer wages above 30 than in the Baseline treatment. This can be seen from Table 1 ('Offers $\geq 30$ ') which shows that in stage 2 the percentage of public and referral offers exceeding the reservation wage of the H-type worker is $21 \%$ in Referral and only $13 \%$ in Baseline (Mann-Whitney U, $p=0.017$ ). Regressions (5) and (6) in Table 2 reveal that this difference is mainly due to the behavior in the second half of the market opening time $(p<0.001)$. 


\subsection{Hires and Efficiency}

Here we explore if the possibility of hiring via referrals helps to overcome adverse selection, that is, if it increases the number of H-type hires and thus promotes efficiency. As before we state first the result followed by statistical support.

Result 5. Both in stage 1 and 2, the number and percentage of H-type workers hired is higher in the Referral treatment than in the Baseline treatment. Consequently, overall efficiency is also higher in the Referral treatment than in the Baseline treatment.

In Table 1 the rows labeled 'Hires' present respectively the average number and the percentage of $\mathrm{H}$ and L-type hires for each treatment and market stage. First observe that the sum of $\mathrm{H}$ and L-type hires in both treatments and both stages is with 3.6 to 3.7 close to the maximum of 4 hires. In both stages, the total number of hires is not significantly different between the Referral and the Baseline treatment (Mann-Whitney $\mathrm{U}, p>0.404){ }^{18}$ Importantly, however, significantly more H-type workers are hired in Referral than in Baseline ( $p=0.042$ in stage $1, p=0.016$ in stage $2, p=0.021$ overall). The opposite holds for the number of L-type hires $(p=0.098$ in stage $1, p=0.020$ in stage $2, p=0.053$ overall). Consequently, in Referral also the percentage of H-type workers among all hires is with $35 \%$ in stage 1 and $34 \%$ in stage 2 significantly larger than in Baseline with corresponding percentages of only $25 \%$ in stage 1 and $22 \%$ in stage 2 ( $p=0.044$ in stage $1, p=0.006$ in stage $2, p=0.017$ overall).

To test for treatment differences in achieved efficiency we use an efficiency measure defined as realized gains from trade over the maximally possible gains from trade. The latter is achieved with three H-type and one L-type hires and is thus given by $3 *(60-30)+1 *(20-10)=100$. In Table 1, the row labeled 'Efficiency' reports the realized efficiency levels for both market stages in both treatments. It shows that the availability of referral offers increases efficiency by 10 percentage points $(p=0.028)$. In the two stages two different channels are responsible for the increased efficiency in the Referral treatment. In stage 1, efficiency is increased by firms raising wages in anticipation of the benefit of stage $1 \mathrm{H}$-type workers' social ties. In stage 2, efficiency is increased directly by firms hiring H-type workers through referral offers. Taken together, these observations confirm Hypothesis 3 and constitute clear evidence for the value of social ties in alleviating adverse selection.

\subsection{Individual Level Analysis: Risk Aversion, Profits and Efficiency}

Having established statistical support for our model-based hypotheses, we now take a more detailed look at individual strategies. For ease of exposition, we pool the data from stage 1 and 2. We first look into firms' strategies followed by an exploration of workers' strategies.

\footnotetext{
${ }^{18}$ All $p$-values reported in this sub-section are coming from non-parametric Mann-Whitney U tests with session averages as unit of observation.
} 


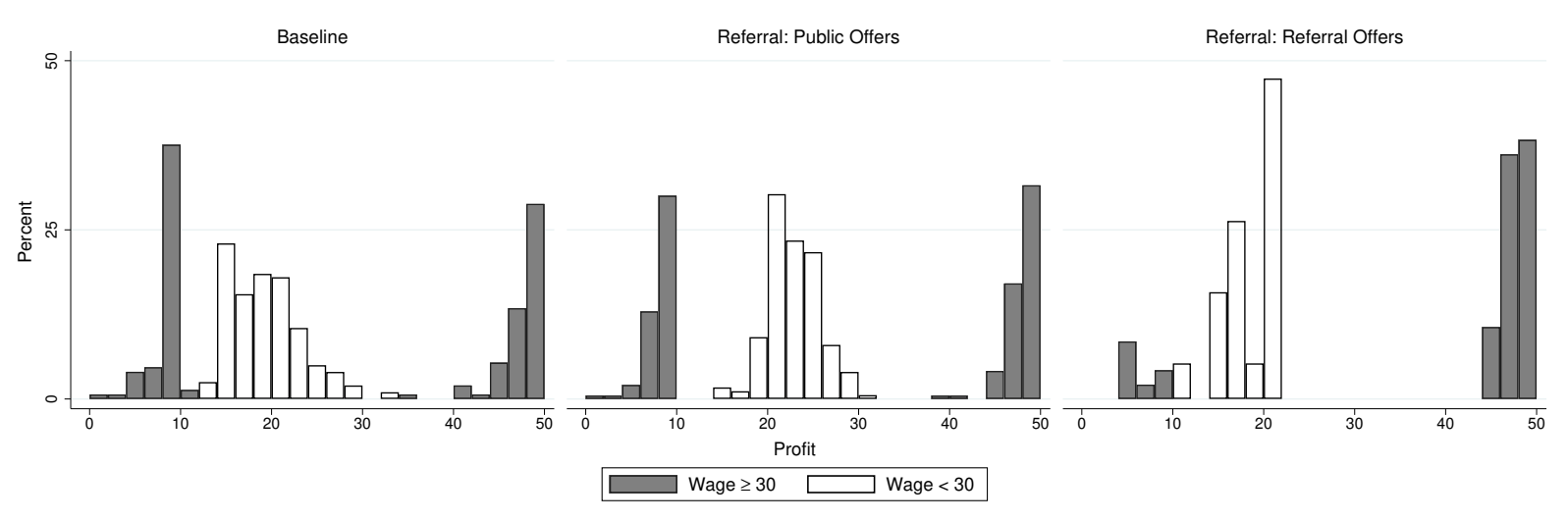

Figure 3: Firm Profits

Notes: Histogram of firm profits separated by whether the accepted wage exceed an H-type worker's reservation wage of 30. Data includes both stages except in the third histogram as referral offers are only made in stage 2 of treatment Referral.

Given the patterns of offers observed in Figure 2, it is reasonable to focus on two main strategies firms may apply. One strategy is to target L-type workers by offering a wage below 30, even towards the end of the market opening time. According to our model, such a strategy should primarily be used by risk averse firms. A complementary strategy firms may follow is attempting to hire H-type workers by offering wages of at least 30. This is risky, however, because this strategy may lead to hires of L-type workers at relatively high wages. Consequently such a strategy should be used by relatively less risk averse firms.

Figure 3 depicts the distribution of firms' profits for these two strategies. When the accepted wage offer is below the H-type workers' reservation wage of 30, profits are approximately uni-modal and centered around 20 (transparent bars). Hiring at wages at or above 30 leads to a bi-modal distribution of profits, with profits being either above 45 or below 10 (black bars). The frequency of hiring an H-type when the wage is at or above 30 is $51 \%$ in Baseline and $54 \%$ in the public market of the Referral treatment. Thus, by using one of the descried strategies, participants in the role of firms essentially choose between a certain, intermediate profit and a gamble with a low and high profits outcome.

The regression analyses reported in Table 4, Models (1)-(4), look at how firms' different strategies impact their profits. Model (1) shows that in Baseline average firm profit is 7.25 points higher when the accepted offer is at least 30 compared to when it is below 30 . This can be interpreted as a risk premium for making a high wage offer. Model (2) adds as an explanatory variable a dummy for the hired worker's productivity type. It shows that if the hired worker is an L-type, firms hiring at wages at or above 30 earn on average 12.74 points less than firms making low offers. However, if the hired worker is an H-type, firms hiring at the higher wages earn on average $26.76(=-12.74+39.50)$ more than firms hiring at lower wages. Accounting for the constant, this 
Table 4: Firm and L-type Worker Profits in Dependence of Wage Offers and Hirings

\begin{tabular}{|c|c|c|c|c|c|c|c|c|}
\hline \multirow[t]{3}{*}{ Dep. Var. } & \multicolumn{4}{|c|}{ Firm Profit } & \multicolumn{4}{|c|}{ L-type Worker Profit } \\
\hline & \multicolumn{2}{|c|}{ Baseline } & \multicolumn{2}{|c|}{ Referral } & \multicolumn{2}{|c|}{ Baseline } & \multicolumn{2}{|c|}{ Referral } \\
\hline & (1) & $(2)$ & $(3)$ & $(4)$ & $(5)$ & (6) & $(7)$ & $(8)$ \\
\hline Offer $\geq 30$ & $\begin{array}{l}7.25^{* *} \\
(3.32)\end{array}$ & $\begin{array}{c}-12.74^{* * *} \\
(1.49)\end{array}$ & $\begin{array}{c}7.08^{* * *} \\
(1.33)\end{array}$ & $\begin{array}{c}-14.89^{* * *} \\
(0.66)\end{array}$ & $\begin{array}{l}5.20^{*} \\
(2.75)\end{array}$ & $\begin{array}{c}11.68^{* * *} \\
(1.64)\end{array}$ & $\begin{array}{c}3.97^{* * *} \\
(1.13)\end{array}$ & $\begin{array}{c}14.77^{* * *} \\
(0.85)\end{array}$ \\
\hline H-type & & $\begin{array}{c}39.50^{* * * *} \\
(0.42)\end{array}$ & & $\begin{array}{c}40.04^{* * *} \\
(0.14)\end{array}$ & & & & \\
\hline Not Hired & & & & & & $\begin{array}{c}-22.68^{* * *} \\
(0.93)\end{array}$ & & $\begin{array}{c}-22.36^{* * *} \\
(0.33)\end{array}$ \\
\hline Referral Offer (RO) & & & $\begin{array}{c}-6.47^{* * * *} \\
(1.65)\end{array}$ & $\begin{array}{c}-4.30^{* * *} \\
(0.60)\end{array}$ & & & $\begin{array}{c}5.74^{* * *} \\
(1.21)\end{array}$ & $\begin{array}{c}4.58^{* * *} \\
(0.78)\end{array}$ \\
\hline Offer $\geq 30 \times \mathrm{RO}$ & & & $\begin{array}{c}17.19^{* * *} \\
(1.47)\end{array}$ & $\begin{array}{c}4.01^{* * *} \\
(0.65)\end{array}$ & & & $\begin{array}{c}7.01^{* * * *} \\
(1.49)\end{array}$ & $\begin{array}{c}-3.13^{* *} \\
(1.34)\end{array}$ \\
\hline Constant & $\begin{array}{c}20.88^{* * *} \\
(2.80)\end{array}$ & $\begin{array}{c}19.97^{* * *} \\
(1.42)\end{array}$ & $\begin{array}{c}24.38^{* * *} \\
(2.42)\end{array}$ & $\begin{array}{c}22.10^{* * *} \\
(0.63)\end{array}$ & $\begin{array}{c}20.88^{* * *} \\
(0.69)\end{array}$ & $\begin{array}{c}21.14^{* * *} \\
(1.03)\end{array}$ & $\begin{array}{c}18.77^{* * *} \\
(1.80)\end{array}$ & $\begin{array}{c}18.51^{* * *} \\
(0.58)\end{array}$ \\
\hline Observations & 349 & 349 & 429 & 429 & 299 & 299 & 356 & 356 \\
\hline Subjects (Sessions) & $20(5)$ & $20(5)$ & $24(6)$ & $24(6)$ & $60(5)$ & $60(5)$ & $72(6)$ & $72(6)$ \\
\hline
\end{tabular}

Notes: Linear mixed effects models with subject and session random intercept; standard errors clustered on sessions in parentheses, ${ }^{*} p<0.10,{ }^{* *} p<0.05,{ }^{* * *} p<0.01$. Bootstrap standard errors yield qualitatively identical results. Data include both stages. Period and stage dummies included in all regressions. The reference groups for Baseline are wages below 30 in models (1) and (5), wages below 30 with an L-type worker in model (2), and wages below 30 if hired in model (6). The reference group for Referral are public market wages below 30 in models (3) and (7), public market wages below 30 with an L-type worker in model (4), and public market wages below 30 if hired in model (8).

implies that firms could either go for a certain payoff of 19.97 (when making offers around 20) or a $50-50$ bet between receiving a payoff of 7.23 (=19.97 - 12.74) and $46.73(=19.97-12.74+39.50)$. From this it follows that in the Baseline treatment, indifference between the certain payoff and the gamble implies a CARA coefficient of 0.044 (or a CRRA coefficient of 0.89). ${ }^{19,20}$ Models (3) and (4) report the regressions for the Referral treatment. Results are very similar with the main differences that offering high wages is particularly profitable for referral offers.

In switching to workers' strategies we note that they face a different trade-off than firms. In each market (with 4 firms and 6 workers) at least 2 workers will not be hired. L-type workers can either choose to accept a wage below 30 or to hold out for higher wages with the risk of being not hired. Models (5) to (8) in Table 4 provide information on the payoff consequences of both strategies. Models (5) and (7) show that in the public markets there is a risk premium of 5.2 (in Baseline) and 3.97 (in Referral) when holding out for a wage of at least 30. From the constant in Model (6)

\footnotetext{
${ }^{19}$ These average risk coefficients are broadly in line with the literature on risk elicitation, see e.g. Holt and Laury (2002)'s high-stakes treatment and Dave et al. (2010).

${ }^{20}$ In Online Appendix C.2 we show that consistent with these results subjects that are more likely to target $\mathrm{H}$-types on average earn more than subjects who tend to make only low offers.
} 


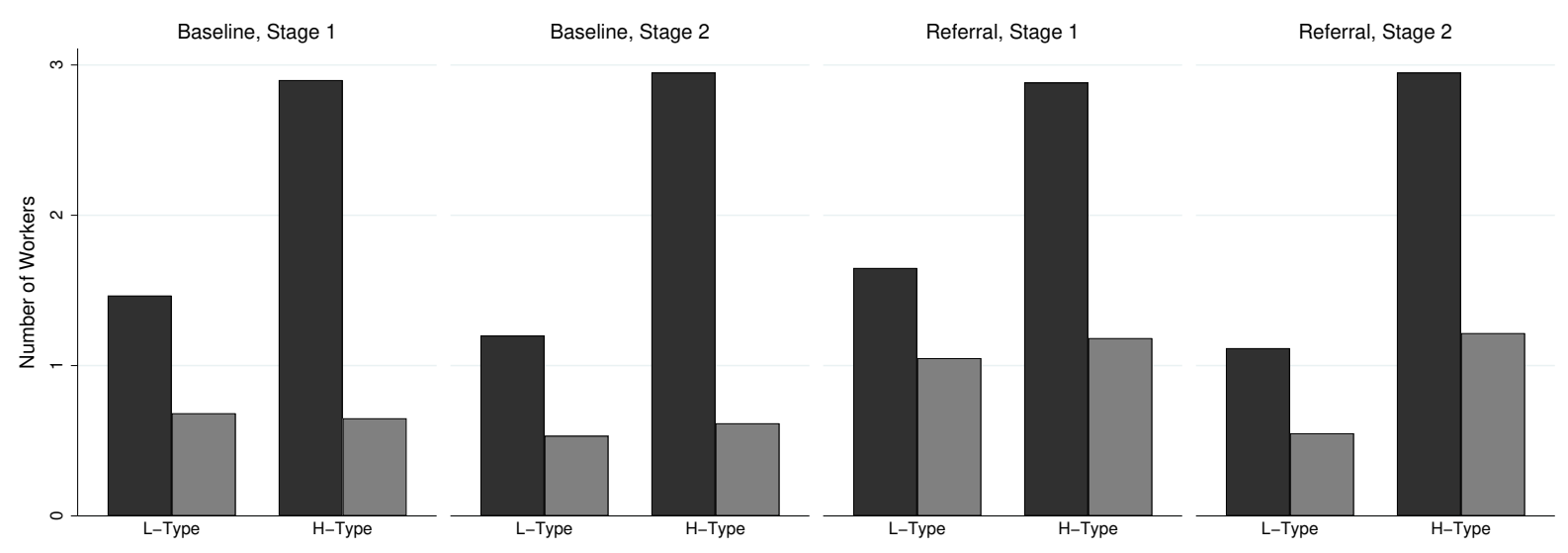

Figure 4: Supply and Hires of Workers at (and above) H-Type Worker's Reservation Wage

Notes: Black bars show the average number of workers (separated by treatments, stages, and productivity type) who are active on the market when wage offers are equal to H-type workers' reservation wage of 30 . Grey bars show the average number of workers who are indeed hired at wages at or above 30.

we see that accepting an offer below 30 yields on average a payoff of 21.14 (note that workers who accept low wages are almost always hired). In addition, it indicates that holding out for wage offers of at least 30, either results in a payoff of $32.82(=21.14+11.68)$ if hired or a payoff of 10.14 $(=21.14+11.68-22.68)$ if not hired. The latter is just the L-type workers' reservation wage. The frequency of an L-type who did not accept offers below 30 is $74 \%$. Therefore, for an L-type worker holding out for a high wage is equivalent to a gamble which earns 32.82 with probability 0.74 and 10.14 with probability 0.26 , while accepting a low wage gives the option of earning 21.14 almost certainly. From this, the implied risk coefficients of L-type workers are 0.098 for CARA and 1.58 for CRRA. Similar conclusions can be drawn for the Referral treatment.

Together the implied risk aversion parameters of firms and workers can explain why relative to the second-best efficient outcome too many L-type workers are hired in both treatments. We refer to second-best efficiency here as the relevant benchmark because in environments with adverse selection first-best outcomes can typically not be supported at equilibrium by any mechanism (Samuelson, 1984).

Interestingly, the implied degree of risk aversion appears to be much higher for L-type workers than for firms. A possible explanation relates to the fact that in comparison to H-type workers, L-type workers are much more likely to accept a wage offer of at least 30. The black bars in Figure 4 show the number of workers who are still on the market when wage offers reach the H-type workers' reservation wage of 30. Notice that at such wages all three H-type workers are still on the market and can be hired, but more than half of the L-type workers have already left the market because they accepted a lower wage. The grey bars show the number of workers who are eventually hired at a wage equal to or above 30 . 
In the Baseline treatment the number of L-type and H-type workers hired at such wages is the same, despite the fact that there are many more H-type workers available for hire. An intuitive reason for this is that for wages close to H-type workers' reservation wage the gains from accepting an offer are much larger for L-type workers than for H-type workers. Thus, L-type workers tend to be much quicker than H-type workers in accepting offers of 30 or slightly above. If L-type workers do not fully anticipate this they may underestimate the probability of being hired when holding out for a high wage, in which case we would overestimate their risk aversion. Panel 'Referral, Stage 1' in Figure 4 shows a similar picture for stage 1 of the Referral treatment. In panel 'Referral, Stage 2' of the figure, the number of H-type workers hired at wages equal to or above 30 is larger than the number of L-type workers, which arises because referral offers are targeted primarily at H-type workers. ${ }^{21}$

\section{Conclusion}

We investigate in a laboratory experiment whether firms succeed in alleviating the negative effects of information asymmetry in labor markets, by using social ties of their employees. In our set-up we mirror the fact that employee referrals are informative about the productivity of prospective workers because individuals that are part of the same social network tend to have similar abilities. We explore the causal effect of social ties and of hiring through referrals by comparing behavior in two treatments. In both treatments low and high productivity workers are on the market and productivity is private information. In the Baseline treatment there are no social ties among workers and firms can hire workers only in a competitive public market. In the Referral treatment we introduce social ties between workers which firms can use to make referral offers, thereby potentially mitigating adverse selection effects. We also propose a theoretical model and derive hypothesis for the two treatments.

The empirical results provide strong support for the hypotheses. We find that firms use social ties of 'old' workers and referrals to hire 'new' workers, which in turn alleviates adverse selection effects. More high productivity workers are hired and efficiency is higher in the Referral treatment than in the Baseline treatment. Remarkably, we find that social ties lead to higher wages not only for 'new' workers hired via referrals but also induce higher wages for previously employed 'old' workers who are hired solely on a competitive public market. The reason for this spill-over effect is that higher wages increase the probability of hiring high productivity workers, which allows firms to access these workers' valuable social ties in the future.

\footnotetext{
${ }^{21}$ Another more speculative explanation relates to the difference in the nature of the gamble firms and workers are facing on the market. Specifically, a worker may derive disutility from the outcome where she is not hired, beyond the immediate payoff consequences. Such a "displeasure of being unemployed" is reminiscent of the opposite idea of the "joy of winning" in the auction literature (e.g. Dohmen et al., 2011).
} 
On a more general level, our study contributes to the question of how to promote efficiency in markets impaired by asymmetric information. Our results are encouraging, as firms effectively utilize social ties which improves market outcomes. But we also observe that adverse selection does not vanish because - mainly risk averse firms - make too low offers to 'old' workers hired in a competitive market. This leads to too many low productivity hires. However, in our experiment we only explore two stages, where only on the second stage referral offers are possible. It is conceivable that in the longer run the positive effect of referral offers may be self-enforcing such that efficiency may increase over time. Such a longer and more dynamic environment would be an interesting future research avenue. Also, to investigate causal effects, in our setting social ties where exogenously imposed. In the field, however, social ties are endogenous and it would be interesting to further explore the interaction between endogenous social ties (perhaps formed at the work place), referral offers and adverse selection in the labor market.

Montgomery (1991b) and Calvo-Armengol and Jackson (2004) present theoretical network models where individuals who are not well-connected are at a disadvantage and thus networks can perpetuate inequality. Our positive evaluation of referral offers may need reassessment if their informational value comes at the cost of an increase in inequality. At the same time it appears that social groups that are less well-connected (e.g., first-time job seekers or immigrants) are often those about which there exists little objective information. Employee referrals, as one source of credible information, could thus be particularly effective for such groups and may even mitigate labor market discrimination. Exploring which of these effects dominates seems a fruitful avenue for future research.

Finally, in line with many other studies we have focused on potential beneficial effects of social ties in labor markets. However, recently evidence emerged indicating that recruitment via job networks may disadvantage qualified women (Beaman et al., 2018). Further research for better understanding which mechanisms could help overcoming such gender discrimination in referral networks appears another interesting future research line.

\section{References}

Akerlof, George A., "The market for "lemons": Quality uncertainty and the market mechanism," The Quarterly Journal of Economics, 1970, pp. 488-500.

Akerlof, George A, "Labor contracts as partial gift exchange," The Quarterly Journal of Economics, 1982, 97 (4), 543-569.

_ , "Gift exchange and efficiency-wage theory: Four views," The American Economic Review, 1984, 74 (2), 79-83. 
Andreoni, James, "Satisfaction Guaranteed: When Moral Hazard meets Moral Preferences," American Economic Journal: Microeconomics, 2017, 74 (5), 1365-1384.

Arrow, Kenneth J., "Uncertainty and the welfare economics of medical care," The American Economic Review, 1963, 53 (5), 941-973.

Beaman, Lori A., "Social networks and the dynamics of labour market outcomes: Evidence from refugees resettled in the US," The Review of Economic Studies, 2011, 79 (1), 128-161.

_, Niall Keleher, and Jeremy Magruder, "Do job networks disadvantage women? Evidence from a recruitment experiment in Malawi," Journal of Labor Economics, 2018, 36 (1), 121-157.

Beaman, Lori and Jeremy Magruder, "Who gets the job referral? Evidence from a social networks experiment," The American Economic Review, 2012, 102 (7), 3574-3593.

Bochet, Olivier and Simon Siegenthaler, "Better Later than Never? An Experiment on Bargaining under Adverse Selection," International Economic Review, 2018, 59 (2), 947-972.

Boorman, Scott A, "A combinatiorial optimization model for transmission of job information through contact networks," The Bell Journal of Economics, 1975, pp. 216-249.

Brown, Martin, Armin Falk, and Ernst Fehr, "Relational contracts and the nature of market interactions," Econometrica, 2004, 72 (3), 747-780.

Brown, Meta, Elizabeth Setren, and Giorgio Topa, "Do informal referrals lead to better matches? Evidence from a firms employee referral system," Journal of Labor Economics, 2016, 34 (1), 161-209.

Burks, Stephen V., Bo Cowgill, Mitchell Hoffman, and Michael Housman, "The value of hiring through employee referrals," The Quarterly Journal of Economics, 2015, 130 (2), 805-839.

Calvó-Armengol, Antoni, "Job contact networks," Journal of Economic Theory, 2004, 115 (1), 191-206.

Calvo-Armengol, Antoni and Matthew O Jackson, "The effects of social networks on employment and inequality," The American Economic Review, 2004, 94 (3), 426-454.

Calvó-Armengol, Antoni and Yves Zenou, "Job matching, social network and word-ofmouth communication," Journal of Urban Economics, 2005, 57 (3), 500-522.

Cooper, David J. and John H. Kagel, "Other regarding preferences: A selective survey of experimental results," The Handbook of Experimental Economics, 2016, 2, 217-289.

Currarini, Sergio, Matthew O. Jackson, and Paolo Pin, "An economic model of friendship: Homophily, minorities, and segregation," Econometrica, 2009, 77 (4), 1003-1045. 
Dave, Chetan, Catherine C. Eckel, Cathleen A. Johnson, and Christian Rojas, "Eliciting risk preferences: When is simple better?," Journal of Risk and Uncertainty, 2010, 41 (3), 219-243.

Dohmen, Thomas, Armin Falk, Klaus Fliessbach, Uwe Sunde, and Bernd Weber, "Relative versus absolute income, joy of winning, and gender: Brain imaging evidence," Journal of Public Economics, 2011, 95 (3-4), 279-285.

Dustmann, Christian, Albrecht Glitz, Uta Schönberg, and Herbert Brücker, "Referralbased job search networks," The Review of Economic Studies, 2015, 83 (2), 514-546.

Fafchamps, Marcel and Alexander Moradi, "Referral and job performance: Evidence from the Ghana colonial army," Economic Development and Cultural Change, 2015, 63 (4), 715-751.

Falk, Armin, Stephan Meier, and Christian Zehnder, "Do lab experiments misrepresent social preferences? The case of self-selected student samples," Journal of the European Economic Association, 2013, 11 (4), 839-852.

Fehr, Ernst, Georg Kirchsteiger, and Arno Riedl, "Does fairness prevent market clearing? An experimental investigation," The Quarterly Journal of Economics, 1993, 108 (2), 437-459.

_ , Simon Gächter, and Georg Kirchsteiger, "Reciprocity as a contract enforcement device: Experimental evidence," Econometrica: Journal of the Econometric Society, 1997, pp. 833-860.

Fischbacher, Urs, "z-Tree: Zurich toolbox for ready-made economic experiments," Experimental Economics, 2007, 10 (2), 171-178.

Galenianos, Manolis, "Hiring through referrals," Journal of Economic Theory, 2014, 152, 304323.

Galeotti, Andrea and Luca Paolo Merlino, "Endogenous job contact networks," International Economic Review, 2014, 55 (4), 1201-1226.

Granovetter, Mark, "Economic action and social structure: The problem of embeddedness," American Journal of Sociology, 1985, 91 (3), 481-510.

_, Getting a job: A study of contacts and careers, The University of Chicago Press, 1995.

Greiner, Ben, "Subject pool recruitment procedures: organizing experiments with ORSEE," Journal of the Economic Science Association, 2015, 1 (1), 114-125.

Heath, Rachel, "Why do firms hire using referrals? Evidence from bangladeshi garment factories," Journal of Political Economy, 2018, 126 (4), 1691-1746.

Hensvik, Lena and Oskar Nordström Skans, "Social networks, employee selection, and labor market outcomes," Journal of Labor Economics, 2016, 34 (4), 825-867. 
Holt, Charles A. and Susan K. Laury, "Risk aversion and incentive effects," The American Economic Review, 2002, 92 (5), 1644-1655.

Hoppe, Eva I. and Patrick W. Schmitz, "Do sellers offer menus of contracts to separate buyer types? An experimental test of adverse selection theory," Games and Economic Behavior, 2015, 89, 17-33.

Ioannides, Yannis M. and Linda D. Loury, "Job information networks, neighborhood effects, and inequality," Journal of Economic Literature, 2004, 42 (4), 1056-1093.

Jackson, Matthew O., "An overview of social networks and economic applications," in "The Handbook of Social Economics," Vol. 1, North Holland Press Amsterdam, 2010, pp. 511-585.

_, Social and economic networks, Princeton University Press, 2010.

Kübler, Dorothea, Wieland Müller, and Hans-Theo Normann, "Job-market signaling and screening: An experimental comparison," Games and Economic Behavior, 2008, 64 (1), 219-236.

Kugler, Adriana D., "Employee referrals and efficiency wages," Labour Economics, 2003, 10 (5), 531-556.

Levitt, Steven D and John A List, "What do laboratory experiments measuring social preferences reveal about the real world?," Journal of Economic Perspectives, 2007, 21 (2), 153-174.

Loury, Linda Datcher, "Some contacts are more equal than others: Informal networks, job tenure, and wages," Journal of Labor Economics, 2006, 24 (2), 299-318.

Mas-Colell, Andreu, Michael Dennis Whinston, Jerry R Green et al., Microeconomic theory, Vol. 1, Oxford university press New York, 1995.

McPherson, Miller, Lynn Smith-Lovin, and James M Cook, "Birds of a feather: Homophily in social networks," Annual Review of Sociology, 2001, 27 (1), 415-444.

Mimra, Wanda and Christian Waibel, "(Non)Exclusive Contracting Under Adverse Selection: An Experiment," 2017. Working paper available at SSRN: https://ssrn.com/abstract=3037097.

Montgomery, James D., "Social networks and labor-market outcomes: Toward an economic analysis," The American Economic Review, 1991, 81 (5), 1408-1418.

_, Social networks and persistent inequality in the labor market, Center for Urban Affairs and Policy Research, 1991.

Mortensen, Dale T and Tara Vishwanath, "Personal contacts and earnings: It is who you know!," Labour Economics, 1994, 1 (2), 187-201. 
Munshi, Kaivan, "Networks in the modern economy: Mexican migrants in the US labor market," The Quarterly Journal of Economics, 2003, 118 (2), 549-599.

Pallais, Amanda and Emily Glassberg Sands, "Why the referential treatment? Evidence from field experiments on referrals," Journal of Political Economy, 2016, 124 (6), 1793-1828.

Pellizzari, Michele, "Do friends and relatives really help in getting a good job?," Industrial Labor \& Relations Review, 2010, 63 (3), 494-510.

Pissarides, Christopher A, Equilibrium unemployment theory, MIT press, 2000.

Rees, Albert, "Information networks in labor markets," The American Economic Review, 1966, $56(1 / 2), 559-566$.

Riedl, Arno and Paul Smeets, "Why do investors hold socially responsible mutual funds?," The Journal of Finance, 2017, 72 (6), 2505-2550.

Samuelson, William, "Bargaining under asymmetric information," Econometrica: Journal of the Econometric Society, 1984, pp. 995-1005.

Schmutte, Ian M., "Job referral networks and the determination of earnings in local labor markets," Journal of Labor Economics, 2014, 33 (1), 1-32.

Siegenthaler, Simon, "Meet the lemons: An experiment on how cheap-talk overcomes adverse selection in decentralized markets," Games and Economic Behavior, 2017, 102, 147-161.

Topa, Giorgio, "Social interactions, local spillovers and unemployment," The Review of Economic Studies, 2001, 68 (2), 261-295.

_ , "Labor markets and referrals," in "Handbook of Social Economics," Vol. 1, Elsevier, 2011, pp. 1193-1221.

Wilson, Charles, "The nature of equilibrium in markets with adverse selection," The Bell Journal of Economics, 1980, pp. 108-130.

Zenou, Yves, "Social interactions and the labor market," Revue d'économie politique, 2013, 123 (3), 307-331. 


\section{A Equilibrium Characterization}

This appendix derives the market equilibria. We will construct the symmetric equilibria. We also focus on the market structure relevant to the experiment where $n_{S} \equiv n_{L}+n_{H} \geq n_{F}>n_{L}$. Moreover, $P_{H}-\lambda_{H}>$ $P_{L}-\lambda_{L}$. Let $\hat{n}_{F} \equiv n_{F}-1$ and similarly for workers.

\section{A.1 Equilibrium in Baseline}

It is sufficient to discuss equilibrium behavior in stage 1 (identical predictions apply to stage 2 since the stages are independent). Notice that $n_{F} \leq n_{S}$ implies that the highest offer is $\lambda_{H}$. Moreover, all firms always include $\lambda_{H}$ in their set of wage offers: We will show below that at equilibrium L-type workers accept offers $w^{*}<\lambda_{H}$ with probability (w.p.) 1. Thus, when offering a wage $w^{*}<\lambda_{H}$, it is always profitable for firms to also offer $\lambda_{H}$, as the latter offer will only be accepted if no L-type workers are left in the market.

Consider next the following equation for L-type workers:

$$
u_{L}(w)=\frac{n_{F}-q}{n_{S}-q} u_{L}\left(\lambda_{H}\right)+\frac{n_{S}-n_{F}}{n_{S}-q} u_{L}\left(\lambda_{L}\right) .
$$

If $q=\hat{n}_{L}$, the wage $\underline{w}$ solving (A.1) represents a lower bound for acceptable wages. For any lower wage, an L-type worker prefers to wait for the offer $\lambda_{H}$, even if $q=\hat{n}_{L}$ firms and other L-type workers have left the market and the probability to be hired at a wage of $\lambda_{H}$ is only $\left(n_{F}-\hat{n}_{L}\right) /\left(n_{S}-\hat{n}_{L}\right)$. Similarly, the wage $\bar{w}_{1}$ solving (A.1) for $q=0$ yields the wage level above which L-type workers accept with probability 1.

On the firms' side, an upper bound for wage offers below $\lambda_{H}$ is reached if they prefer offering $\lambda_{H}$ immediately rather than hiring an L-type worker at a wage that exceeds $\bar{w}_{2}$ :

$$
u_{F}\left(P_{L}+B-\bar{w}_{2}\right)=\Psi\left(\lambda_{H}\right) .
$$

where

$$
\Psi\left(\lambda_{H}\right)=\frac{n_{L}}{n_{S}} u_{F}\left(P_{L}+B-\lambda_{H}\right)+\frac{n_{H}}{n_{S}} u_{F}\left(P_{H}+B-\lambda_{H}\right) .
$$

denotes a firm's expected utility when offering $\lambda_{H}$ and all workers are still in the market. The parameter $B$ is a baseline productivity, set to $B=20$ in the experiment.

Suppose that at equilibrium firms offer $\left\{\lambda_{H}\right\}$ with probability $\beta^{*}$ and $\left\{w^{*}, \lambda_{H}\right\}$ with probability $1-\beta^{*}$. We claim that $w^{*}<\lambda_{H}$ can be supported as an equilibrium wage only if $w^{*} \in\left[\underline{w}, \min \left(\bar{w}_{1}, \bar{w}_{2}\right)\right]$. We prove the claim:

- From (A.1) it follows directly that wages below $\underline{w}$ are always rejected. Further, we must have $w^{*} \leq \bar{w}_{2}$ for if not (A.2) implies that firms strictly prefer to offer $\left\{\lambda_{H}\right\}$. Finally, we must have $w^{*} \leq \bar{w}_{1}$. If 
not, firms would have an incentive to offer a lower wage. Let $n_{F L}$ be the number of firms offering $\left\{w^{*}, \lambda_{H}\right\}$. If $n_{F L} \leq n_{L}$, a firm is guaranteed to hire an L-type workers with any offer $w>\bar{w}_{1}$. If $n_{F L}>n_{L}$ firms may not hire an L-type worker (if other firms offer more), but in this case the firm prefers to hire at the wage $\lambda_{H}$ as it implies that they hire an H-type w.p. 1 (and earn strictly more due to the higher gains from trade). Notice that L-type workers must accept $w^{*}<\lambda_{H}$ with probability 0 or 1 . If they accept with a positive probability less than 1 , firms could slightly lower the wage to $w^{*}-\epsilon$, knowing that L-type workers would accept such an offer in return for a strictly higher probability to get hired if $n_{F L} \leq n_{L}$ (as wages are cleared from below) or they would hire an H-type at $\lambda_{H}$ in case $n_{F L}>n_{L}$.

There is more than one possible equilibrium wage level below $\lambda_{H}$. To see this, let $w_{F L} \leq \bar{w}_{1}$ be the solution to (A.1) for $q=\min \left(\hat{n}_{L}, n_{F L}\right)$. If $w^{*}<w_{F L}$, L-type workers reject $w^{*}$ given the realization of $n_{F L}$. If $w^{*} \in\left[w_{F L}, \bar{w}_{1}\right]$, L-type workers face a coordination problem: if $\hat{n}_{L}$ L-type workers accept $w^{*}$ the remaining worker want to accept as well, but similarly if $\hat{n}_{L}$ L-type workers reject $w^{*}$ so does the remaining one. The reason is that the risk of not being hired increases in the number of other L-type workers who accept $w^{*}$, see (A.1). The threshold wage level at which L-type workers switch from accepting $w^{*}$ to rejecting $w^{*}-\epsilon$ can thus be anywhere in $\left[w_{F L}, \bar{w}_{1}\right]$. At the threshold, firms also don't deviate to higher offers, because at equilibrium they are indifferent between offering $\left\{\lambda_{H}\right\}$ and $\left\{w^{*}, \lambda_{H}\right\}$, i.e. they don't want to hire an L-type worker at wage larger than $w^{*}$. Hence, the supportable wage levels can go as low as $w^{*}=\underline{w}$.

Now, offering $\left\{\lambda_{H}\right\}$ yields an expected utility of

$$
U_{F}\left(\left\{\lambda_{H}\right\} ; \hat{n}_{F L}\right)=\frac{n_{L}-\min \left(\hat{n}_{F L}, n_{L}\right)}{n_{S}-\min \left(\hat{n}_{F L}, n_{L}\right)} u_{F}\left(P_{L}+B-\lambda_{H}\right)+\frac{n_{H}}{n_{S}-\min \left(\hat{n}_{F L}, n_{L}\right)} u_{F}\left(P_{H}+B-\lambda_{H}\right) .
$$

Offering $\left\{w^{*}, \lambda_{H}\right\}$ yields an expected utility of

$$
U_{F}\left(\left\{w^{*}, \lambda_{H}\right\} ; \hat{n}_{F L}\right)=\Psi\left(\lambda_{H}\right)
$$

if $w^{*}<w_{F L}$ and of

$$
U_{F}\left(\left\{w^{*}, \lambda_{H}\right\} ; \hat{n}_{F L}\right)=\frac{\min \left(n_{L}, n_{F L}\right)}{n_{F L}} u_{F}\left(P_{L}+B-w^{*}\right)+\left(1-\frac{\min \left(n_{L}, n_{F L}\right)}{n_{F L}}\right) u_{F}\left(P_{H}+B-\lambda_{H}\right)
$$

if $w^{*} \geq w_{F L}$. The equilibrium probability $\beta^{*}$ of offering $\left\{\lambda_{H}\right\}$ renders firms indifferent between $\left\{\lambda_{H}\right\}$ and $\left\{w^{*}, \lambda_{H}\right\}$ :

$$
\sum_{i=0}^{\hat{n}_{F}}\left(1-\beta^{*}\right)^{i}\left(\beta^{*}\right)^{\hat{n}_{F}-i}\left(\begin{array}{c}
\hat{n}_{F} \\
i
\end{array}\right)\left[U_{F}\left(\left\{\lambda_{H}\right\} ; i\right)-U_{F}\left(\left\{w^{*}, \lambda_{H}\right\} ; i\right)\right]=0 .
$$

The solutions to (A.4) - (A.7) for $w^{*}=\underline{w}$ and $w^{*}=\bar{w}_{1}$ give the relevant bounds for the minimum and maximum number of hired L-type workers. The equilibrium reported in Figure 1 is for $w^{*}=\bar{w}_{1}$. Note that if expression (A.7) exceeds 0 even for $\beta=1$, the equilibrium value is $\beta^{*}=1$ (the opposite case never occurs if $n_{F}>n_{L}$ and the gains from trade are larger with H-type workers). 


\section{A.2 Equilibrium in Referral}

We assume that firms and workers in stage 2 can observe the number of firms hiring through referral offers. While in the experiment individuals weren't explicitly informed about referral hires they could observe other firms' behavior in the public market, i.e., a low activity in the public market indicates that many firms intend to or have already hired a worker through a referral offer. Denote the homophily parameter by $\alpha>\max \left(1 / 2, n_{H} / n_{S}\right)$. Without the condition on $\alpha$ the model wouldn't make sense as L-type workers would be more likely than H-type workers to have a social tie to an H-type.

We first show that firms that hired an L-type worker in stage 1 don't make a referral offer in stage 2 .

Lemma A.1. Firms that have hired a stage-1 L-type worker do not benefit from the option to make referral offers in stage 2, i.e., their expected utility when hiring in the public market is larger than when hiring through referral offers.

Proof: Suppose that only firms with an H-type stage-1 worker make a referral offers and in stage 1 all firms offered $\left\{\lambda_{H}\right\}$. Then the expected fraction of H-type workers active in the stage-2 public market is at a minimum and equals

$$
\frac{n_{H}-\frac{n_{H}}{n_{S}} n_{F} \alpha}{n_{S}-\frac{n_{H}}{n_{S}} n_{F}}>1-\alpha
$$

where $\frac{n_{H}}{n_{S}} n_{F}$ is the expected number of firms with a stage- 1 H-type hire and the inequality follows from plugging in $\alpha>\max \left(1 / 2, n_{H} / n_{S}\right)$. Hence the expected fraction of H-type workers active in the stage-2 public market is strictly higher than $1-\alpha$. The latter is the probability to hire an H-type worker through a referral offer for a firm with a stage-1 L-type worker. It follows that for a firm with a stage-1 L-type worker the referral offer of $\left\{\lambda_{H}\right\}$ (or higher) is strictly dominated by the same offer in the public market. Referral offers below $\lambda_{H}$ are inconsequential: they are rejected by H-type workers and L-type workers willing to accept such offers will do so in the public market as well.

When workers choose which wages to accept in the stage-2 public market, they are aware of the number of firms $f$ and the number of workers $s$ still active in the market. Similarly to (A.1), the wage surely accepted by L-type workers $\bar{w}_{1}^{2}(f, s)$ follows from solving

$$
u_{L}\left(\bar{w}_{1}^{2}(f, s)\right)=\frac{f}{s} u_{L}\left(\lambda_{H}\right)+\frac{s-f}{s} u_{L}\left(\lambda_{L}\right) .
$$

The maximum wage $\bar{w}_{2}^{2}$ below $\lambda_{H}$ a firm is willing to offer, similarly to (A.3), follows from

$$
u_{F}\left(P_{L}+B-\bar{w}_{2}^{2}\right)=\Psi\left(\lambda_{H}, f, s\right)
$$

where, letting $\bar{f}=n_{F}-f$ be the number of firms that hired through a referral offer,

$$
\Psi\left(\lambda_{H}, f, s\right)=\sum_{i=0}^{\bar{f}} \alpha^{i}(1-\alpha)^{\bar{f}-i}\left(\begin{array}{c}
\bar{f} \\
i
\end{array}\right)\left(\frac{n_{L}-(\bar{f}-i)}{s} u_{F}\left(P_{L}+B-\lambda_{H}\right)+\frac{n_{H}-i}{s} u_{F}\left(P_{H}+B-\lambda_{H}\right)\right) .
$$


As in the Baseline treatment, firms mix between $\left\{\lambda_{H}\right\}$ and $\left\{w^{2, *}, \lambda_{H}\right\}$. For simplicity, let us focus on $w^{2, *}=\bar{w}_{1}^{2}(f, s)$ (equilibria for the other possible wage levels are derived analogous to the Baseline). Let $f l \leq f$ be the number of firms offering $\left\{w^{2, *}, \lambda_{H}\right\}$. The expected utility conditional on $l, h$, and $f l$ when offering $\left\{\lambda_{H}\right\}$ is

$$
U_{F}\left(\left\{\lambda_{H}\right\} ; l, h, \hat{f l}\right)=\frac{l-\min (\hat{f} l, l)}{s-\min (\hat{f} l, l)} u_{F}\left(P_{L}+B-\lambda_{H}\right)+\frac{h}{s-\min (\hat{f} l, l)} u_{F}\left(P_{H}+B-\lambda_{H}\right) .
$$

Offering $\left\{w^{2, *}, \lambda_{H}\right\}$ yields an expected utility of

$$
U_{F}\left(\left\{w^{2, *}, \lambda_{H}\right\} ; l, h, \hat{f l}\right)=\frac{\min (l, f l)}{f l} u_{F}\left(P_{L}+B-w^{2, *}\right)+\left(1-\frac{\min (f l, l)}{f l}\right)\left[\frac{h}{s-l} u_{F}\left(P_{H}+B-\lambda_{H}\right)\right] .
$$

The equilibrium value $\beta^{2, *}$ with which firms in the public stage-2 market choose to offer $\left\{\lambda_{H}\right\}$ follows from solving

$$
\sum_{i=0}^{\hat{f}}\left(1-\beta^{2, *}\right)^{i}\left(\beta^{2, *}\right)^{\hat{f}-j}\left(\begin{array}{l}
\hat{f} \\
i
\end{array}\right) \sum_{j=0}^{\bar{f}} \alpha^{j}(1-\alpha)^{\bar{f}-j}\left(\begin{array}{l}
\bar{f} \\
j
\end{array}\right)\left[U_{F}\left(\left\{\lambda_{H}\right\} ; l, h, \hat{f} l\right)-U_{F}\left(\left\{w^{2, *}, \lambda_{H}\right\} ; l, h, \hat{f} l\right)\right]=0 .
$$

If (A.14) exceeds 0 even for $\beta^{2, *}=1$, the equilibrium value is $\beta^{2, *}=1$ and vice versa for $\beta^{2, *}=0$. This fully characterizes behavior in the public market of stage 2 in the Referral treatment.

The next question is whether firms that hired an H-type worker in stage 1 will make a referral offer. We denote the probability with which firms make such an offer by $\gamma$. The expected utility when hiring through a referral offer is

$$
\Psi_{r}\left(\lambda_{H}\right)=(1-\alpha) u_{F}\left(P_{L}+B-\lambda_{H}\right)+\alpha u_{F}\left(P_{H}+B-\lambda_{H}\right) .
$$

The expected utility when offering in the stage- 2 public market depends on $\beta^{2, *}$, which we derived in (A.14), on the number $y$ of other firms that have hired at a wage of $\lambda_{H}$ in stage 1 (this is observed), and on the probability $\gamma$ with which such firms make referral offers. The expected utility is given by

$$
U_{F}^{2}(\gamma, y)=\sum_{q=0}^{\min \left(\hat{n}_{H}, y\right)} \frac{\left(\mathbb{1}_{q=0}+\prod_{j=1}^{q-1}\left(\hat{n_{L}}-j\right)\right)\left(\mathbb{1}_{q=y}+\prod_{j=0}^{y-q-1}\left(n_{L}-j\right)\right)}{\prod_{j=0}^{y-1}\left(\hat{n_{S}}-j\right)}\left(\begin{array}{l}
y \\
q
\end{array}\right) \sum_{i=0}^{q} \gamma^{i}(1-\gamma)^{q-i}\left(\begin{array}{l}
q \\
i
\end{array}\right) U_{F}^{2}\left(n_{F}-i\right)
$$

where the first term cycles through the probabilities that in stage $1 q=0$ to $q=\min \left(\hat{n_{H}}, y\right)$ other firms have hired an H-type worker (from the perspective of a firm that hired such a worker), the second term determines the number of referral hires $i$ given $q$, and $U_{F}^{2}\left(n_{F}-i\right)$ is the expected utility in the stage-2 public market if the number of active firms is $f=n_{F}-i$; we omit writing out the latter, as it is found using the same procedure as in (A.12) - (A.14). Notice that $\gamma^{*}=0$ if $\Psi_{r}\left(\lambda_{H}\right)<U_{F}^{2}(0, y), \gamma^{*}=1$ if $\Psi_{r}\left(\lambda_{H}\right) \geq U_{F}^{2}(0, y)$, and $\gamma^{*} \in(0,1)$ solving $\Psi_{r}\left(\lambda_{H}\right)=U_{F}^{2}(0, y)$ otherwise. 
With this in hand, we can now determine the behavior in stage 1. Denote the equilibrium expected utility in the public market of stage 2 conditional on $y$ by $U_{F}^{2, \text { public }}(y)$. Similarly, denote the expected utility in stage 2 when attempting at hiring an H-type worker in stage 1 by $U_{F}^{2, \text { referral }}(y)$. The wage surely accepted by L-type workers $\bar{w}_{1}^{1}$ is exactly the same as in the Baseline, see (A.1). The maximum wage $\bar{w}_{2}^{1}<\lambda_{H}$ a firm is willing to offer is different than in the Baseline, because of the valuable social ties that come with hiring an H-type worker. It solves

$$
u_{F}\left(P_{L}+B-\bar{w}_{2}^{1}\right)+U_{F}^{2, \text { public }}\left(\hat{n_{F}}\right)=\Psi\left(\lambda_{H}\right)+U_{F}^{2, \text { referral }}\left(\hat{n_{F}}\right)
$$

where

$$
U_{F}^{2, \text { referral }}\left(\hat{n_{F}}\right)=\mathbb{1}_{\Psi_{r}\left(\lambda_{H}\right) \geq U_{F}^{2, \text { public }}\left(\hat{n}_{F}\right)}\left(\frac{n_{L}}{n_{S}} U_{F}^{2, \text { public }}\left(\hat{n_{F}}\right)+\frac{n_{H}}{n_{S}} \Psi_{r}\left(\lambda_{H}\right)\right)+\mathbb{1}_{\Psi_{r}\left(\lambda_{H}\right)<U_{F}^{2, \text { public }}\left(\hat{\left.n_{F}\right)}\right)} U_{F}^{2, \text { public }}\left(\hat{n_{F}}\right) .
$$

The left-hand side of (A.17) is the sum of expected utilities over both stages when making low offers in both stages and all other firms offer $\left\{\lambda_{H}\right\}$ in stage 1 and follow the behavior derived above in stage 2 . The right-hand side is the corresponding sum of expected utilities when making only a high offer in stage 1 , hoping to hire a referral worker in stage $2 .{ }^{22}$

As in the Baseline, firms will mix between $\left\{\lambda_{H}\right\}$ and $\left\{\bar{w}_{1}^{1}, \lambda_{H}\right\}$. Let $\beta^{1, *}$ be the probability that firms offer $\left\{\lambda_{H}\right\}$. It is found by solving

$$
\sum_{i=0}^{\hat{n}_{F}}\left(1-\beta^{1, *}\right)^{i}\left(\beta^{1, *}\right)^{\hat{n}_{F}-i}\left(\begin{array}{c}
\hat{n}_{F} \\
i
\end{array}\right)\left[U_{F}\left(\left\{\lambda_{H}\right\} ; i\right)+U_{F}^{2, \text { referral }}\left(\hat{n}_{F}-i\right)-\left(U_{F}\left(\left\{\bar{w}_{1}^{1}, \lambda_{H}\right\} ; i\right)+U_{F}^{2, \text { public }}\left(\hat{n}_{F}-i\right)\right)\right]=0
$$

where $U_{F}\left(\left\{\lambda_{H}\right\} ; i\right)$ and $U_{F}\left(\left\{\bar{w}_{1}^{1}, \lambda_{H}\right\}\right.$ have been derived in (A.4) and (A.6), respectively. If $\bar{w}_{1}^{1}<\bar{w}_{2}^{1}$, $\beta^{1, *}=1$. Notice that because $U_{F}^{2, \text { referral }}\left(\hat{n}_{F}-i\right) \geq U_{F}^{2 \text {,public }}\left(\hat{n}_{F}-i\right)$, the probability $1-\beta^{1, *}$ to observe offers below $\lambda_{H}$ is smaller in stage 1 of the Referral treatment than in the Baseline treatment. This completes the construction of the symmetric market equilibrium.

\footnotetext{
${ }^{22}$ The wage $\bar{w}_{2}^{1}$ is reached if all other firms offer $\left\{\lambda_{H}\right\}$, because this makes offering low more attractive in stage 1 and it also reduces the possible benefits from offering low in stage 2 because hiring an L-type becomes more likely (recall that when offering low a firm always includes a high offer as well, hoping that others will hire all L-types first).
} 